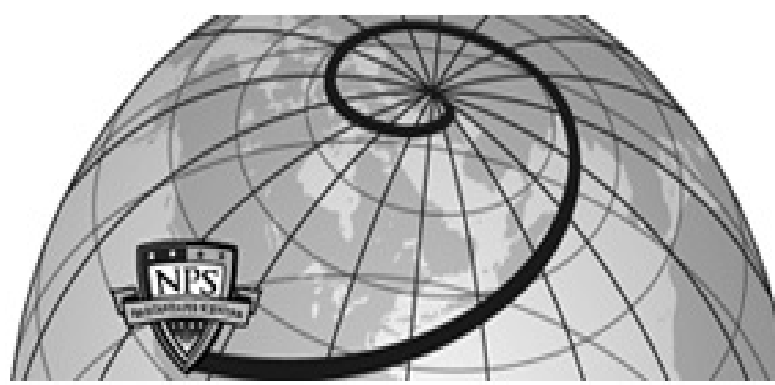

Calhoun: The NPS Institutional Archive DSpace Repository

Role of the Southern Ocean in setting the Atlantic stratification and meridional overturning circulation

Kamenkovich, Igor; Radko, Timour

Journal of Marine Research, 69, 277308, 2011

http://hdl.handle.net/10945/42126

This publication is a work of the U.S. Government as defined in Title 17, United States Code, Section 101. Copyright protection is not available for this work in the United States.

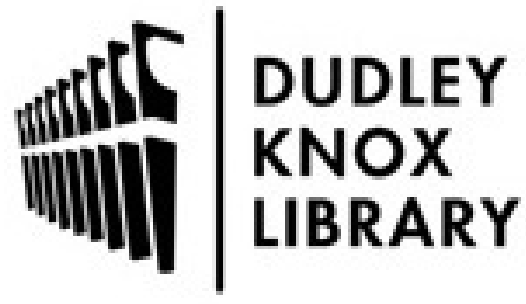

http://www.nps.edu/library
Calhoun is the Naval Postgraduate School's public access digital repository for research materials and institutional publications created by the NPS community. Calhoun is named for Professor of Mathematics Guy K. Calhoun, NPS's first appointed -- and published -- scholarly author.

Dudley Knox Library / Naval Postgraduate School 411 Dyer Road / 1 University Circle Monterey, California USA 93943 


\title{
Role of the Southern Ocean in setting the Atlantic stratification and meridional overturning circulation
}

\author{
by Igor Kamenkovich ${ }^{1}$ and Timour Radko ${ }^{2}$
}

\begin{abstract}
This study examines the importance of the Southern Ocean (SO) stratification in determining the upper cell of the Atlantic meridional overturning circulation (MOC) and stratification. Main results are based on a suite of idealized numerical simulations of the Atlantic with the prescribed density structure at the Atlantic southern boundary, intended to explore the importance of various factors. The results demonstrate that the density distribution at the SO-Atlantic boundary is the key factor controlling the Atlantic stratification and MOC, whereas the main importance of the Ekman and eddy (parameterized) exchanges is in setting the SO stratification. Among all aspects of the SO stratification, the position of the deep isopycnals near the western boundary of the Atlantic basin appears to determine the strength of the MOC for given isopycnal outcrop positions in the North Atlantic. The interplay between the SO stratification and surface density in the North Atlantic is, however, important for the MOC. In particular, the steady-state AMOC response to a negative North Atlantic density anomaly is shown to be amplified if the SO stratification is not allowed to change.
\end{abstract}

\section{Introduction}

Global large-scale thermohaline circulation is a complex phenomenon which involves several major branches often governed by very different dynamics. In particular, the absence of meridional boundaries in the Antarctic Circumpolar Current (ACC) effectively restricts mean meridional flows to the Ekman layers and deep layers next to topographic ridges, whereas the Atlantic meridional overturning circulation (AMOC) is governed by chiefly geostrophic balances. At the same time, the existence of a strong dynamic coupling between the Southern Ocean ("SO" hereafter), defined here as the ocean south of the southern tip of Africa, and the AMOC is now widely accepted. Isopycnals corresponding to the main Atlantic pycnocline outcrop in SO, and the processes that determine large-scale SO stratification can, therefore, also control the Atlantic stratification and MOC. Understanding the dynamics of these SO-AMOC interactions is the main topic of this study. Such understanding is particularly important in light of significant uncertainty in predictions of the response of SO and AMOC to changing atmospheric forcing.

1. Division of Meteorology and Physical Oceanography, Rosenstiel School of Marine and Atmospheric Science, University of Miami, Miami, Florida, 33149, U.S.A. email: ikamenkovich@rsmas.miami.edu

2. Department of Oceanography, Naval Postgraduate School, Monterey, California, 93943, U.S.A. 
Numerical simulations indicate that the intensity of AMOC is sensitive to the southern winds (Toggweiler and Samuels, 1995; 1998; McDermott, 1996; Tsujino and Suginohara, 1999; Gnanadesikan and Hallberg, 2000; Delworth and Zeng, 2008), buoyancy gain at the surface (Hasumi and Suginohara, 1999; Wang et al., 1999; Keeling, 2002; Saenko et al., 2003) and mesoscale eddy transports in SO (Gnanadesikan et al., 2003; Kamenkovich and Sarachik, 2004). Most of these numerical results are based on non eddy-resolving models that may not adequately represent important processes, such as the Agulhas rings (e.g., Donners and Drijfhout, 2004), or the response of mesoscale eddies to changing winds (Hallberg and Gnanadesikan, 2001; 2006; Meredith and Hogg, 2006). However, the key message of the modeling AMOC studies - the importance of the large-scale coupling between SO and Atlantic in controlling the deep stratification and MOC - appears to be robust and is likely to be reflected in more realistic models and in nature as well.

Several studies have made progress in understanding the dynamics of SO-Atlantic interactions. An elegant analytical model of the Atlantic pycnocline by Gnanadesikan (1999) laid a convenient framework for describing the importance of SO-AMOC interactions for the global stratification; this scaling was further explored by Klinger et al. (2003). One of the most important results of Gnanadesikan's study is the demonstration of the existence of the isopycnal pole-to-pole overturning mode, driven by the nearly adiabatic SO processes. Several recent idealized studies demonstrate the existence and explore a regime in which the mid-latitude upwelling is negligible and AMOC is controlled by the SO processes: a reduced-gravity model (Samelson 2004, 2009), a theoretical aqua-planet model (Radko, 2007) and a two-dimensional (zonally averaged) GCM (Sevellec and Fedorov, 2011). Radko and Kamenkovich (2011) introduced a fully analytical model of the semiadiabatic AMOC and Atlanic stratification determined by ventilation of the main isopycnals in the ACC. The model incorporates elements of the adiabatic model of SO stratification (Marshall and Radko, 2003) and mid-latitude ventilated thermocline (Luyten et al., 1983) into a unified model of the MOC. Such SO processes as surface winds, surface buoyancy fluxes and mesoscale eddies, are shown to play a key role in shaping the global stratification and AMOC.

Numerical simulations, capable of resolving mesoscale eddies in idealized ACC-Atlantic basins, confirm these expectations. Henning and Vallis (2004) demonstrate that in the case of strong ACC winds, the stratification is controlled by the combination of ACC wind stress and diapycnal diffusion in the gyre region. Most recent simulations by Wolfe and Cessi (2010) emphasize the importance of the nearly adiabatic ACC dynamics for the Atlantic stratification. They demonstrate that the mid-depth stratification is controlled by SO processes, through the isopycnals that outcrop in both SO and the North Atlantic. They developed a nonlocal scaling that establishes the dependence of AMOC strength on the square of the scale for the depth of isopycnals at the SO-Atlantic boundary; this scale can in turn be determined by eddy diffusivity and winds in the SO.

The present study directly inquires into the mechanisms at the SO-Atlantic boundary that control the Atlantic MOC and stratification. Our central hypothesis is that the stratification 
at the SO-Atlantic boundary, particularly at the western boundary of the Atlantic, strongly influences AMOC strength. Numerical experiments designed to test this hypothesis effectively uncouple the SO-Atlantic system and thereby unravel the complex dynamical links. In doing so, many other important factors, such as surface forcing and internal mixing, will be fixed. The focus of the study is on the dynamics of the upper AMOC cell model version of the North Atlantic Deep Water (NADW) - and on largely adiabatic, along-isopycnal interactions between SO and this upper cell. The dynamics of the second major MOC cell, the Antarctic Bottom Water (AABW), controlled by the diapycnal mixing (Kamenkovich and Goodman, 2000), topography, formation of sea ice and convection near the Antarctic coast (England, 1993) is deliberately excluded from this study. Main conclusions are based on a hybrid model: a full Atlantic GCM in an idealized basin forced by the stratification and buoyancy exchanges at the SO-Atlantic boundary. A somewhat similar approach was taken by Weijer et al. $(1999 ; 2001)$ in a 2D model of the zonal-mean AMOC, forced by prescribed lateral heat/salt fluxes. They explicitly assumed that AMOC is directly affected by buoyancy, not volume fluxes, and demonstrated a sensitivity of AMOC to the lateral buoyancy flux. Our study is fully three-dimensional and dynamically consistent and can explicitly address the importance of volume exchanges between the Atlantic and SO.

This paper is organized as follows. Global and Atlantic-only models (formulated in Section 2) exhibit drastically different Atlantic stratification and MOC (Sections 3a-b). This difference is explained in Section $3 \mathrm{c}$ by the density structure at the Atlantic SO-boundary. A suite of sensitivity experiments described in Section 4 further examines the importance of the stratification at the SO-Atlantic boundary and offers a transparent physical interpretation of the processes at play. Consistent with the central hypothesis, further sensitivity studies (Sections 5a-b) demonstrate a secondary role of the direct contributions of eddy-induced heat/salt exchanges and Ekman transport into AMOC. The northern stratification is, however, highly significant in controlling the strength of the MOC, as is shown in Sections 5c-d. The conclusions are drawn in Section 6.

\section{Formulation of the numerical models}

This study utilizes idealized numerical models intended to represent main features of the global thermohaline circulation. Simulations with global configuration serve as a benchmark and as a source of lateral boundary conditions for the hybrid Atlantic-only simulations. The bulk of the analysis is focused on the influence of SO on the stratification and MOC in the Atlantic basin, and is carried out in the Atlantic-only configuration. This influence can be explained by the position of the isopycnals at the SO-Atlantic boundary, as well as direct effects of the exchanges across this boundary: geostrophic and Ekman volume fluxes and heat/salt fluxes by the mean and eddy currents. By running a suite of Atlantic-only simulations, we will demonstrate in the following sections that the stratification at the SOAtlantic boundary, particularly near the western boundary, is the key factor explaining the 
(a)

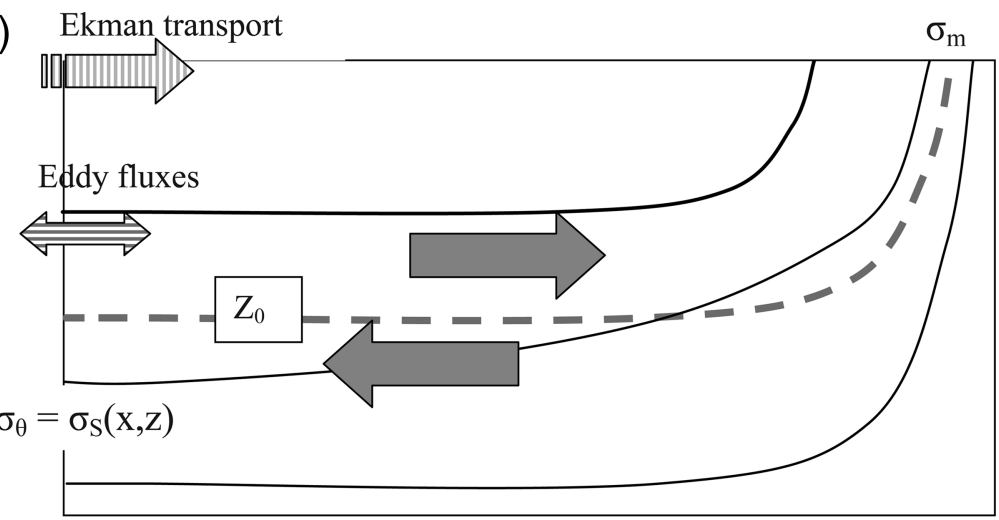

(b)

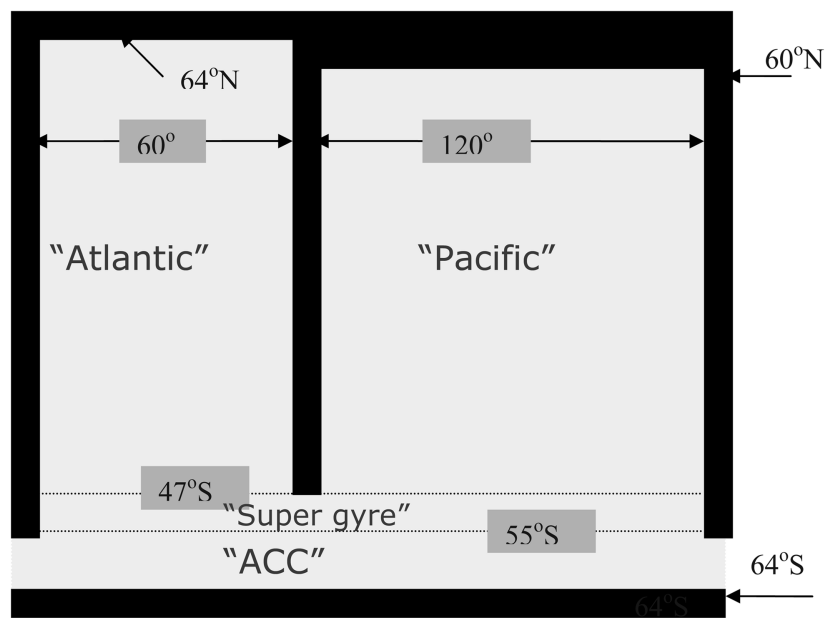

Figure 1. (a) Schema of the stratification and MOC in the Atlantic basin. Thick dashed line shows the "no-flow" surface $Z_{0}$, which separates the northward- and southward-flowing branches of AMOC. Intersection of this surface with isopycnals indicates cross-isopycnal flows (such as upwelling). The density corresponding to the outcrop of the $Z_{0}$ surface is $\sigma_{m}$. (b) Geometry of the global configuration. The Southern Ocean consists of an idealized ACC and the geostrophic "supergyre" region.

control of SO on the Atlantic state, and the importance of the SO-Atlantic exchanges is primarily in sustaining the SO stratification.

\section{a. Global configuration}

In the "global" configuration, two rectangular basins, the "Atlantic" and "Pacific," are connected by a circumpolar channel ("ACC"); as indicated in Figure 1. The model is based on the GFDL MOM3 code (Pacanowski and Griffies, 1999). The model employs a constant 1-degree resolution in the meridional direction and a variable resolution in the zonal 
direction, which changes from 0.5 degree near the solid boundaries in the Atlantic and Pacific basins to 1 degree in the interior of the basins. This configuration allows efficient resolution of the western boundary currents and lower values of horizontal viscosity in models with idealized geometry (Kamenkovich et al., 2000). The bottom is flat everywhere except the ACC region, where evenly distributed seamounts are placed in order to keep the ACC transport to a reasonable value.

The depth of the ocean is limited to 3,000 m, which roughly corresponds to the depth of the North Atlantic Deep Water (NADW) cell in the real ocean (Talley, 2003). There are 30 vertical levels with thicknesses increasing away from the surface. The restricted depth of the domain excludes AABW, which allows us to focus our study on the along-isopycnal interactions in the upper part of the ocean. The importance of deep ocean circulation for the processes under consideration is only briefly addressed in Sections $4 \mathrm{c}-\mathrm{d}$, which discuss simulations with a deeper domain $(4500 \mathrm{~m}, 45$ layers). It will be shown that the main conclusions are not affected by the changes in the domain depth. This is consistent with the idealized modeling study by Kamenkovich and Goodman (2000) who found that, under unchanged surface forcing, AABW tends to passively respond to changes in the NADW cell. Furthermore, Kamenkovich and Sarachik (2004) explicitly demonstrate a very modest role of AABW in explaining the sensitivity of the global stratification to SO-Atlantic eddydriven exchanges of heat and salt.

Vertical diffusivity $k_{v}$ is kept to a value suggested by observations in the ocean above rough topography $-10^{-5} \mathrm{~m}^{2} \mathrm{sec}^{-1}$ (Ledwell et al., 1993; Toole et al., 1994); the diffusion is semi-implicit. Horizontal viscosity is $2 \times 10^{4} \mathrm{~m}^{2} \mathrm{sec}^{-1}$. Bottom friction coefficient is $2.5 \times 10^{-3}$ except in the ACC where it is increased to 0.25 in order to keep the ACC transport to a reasonable value. With the zonal grid spacing of approximately $50 \mathrm{~km}$ (at $\left.30^{\circ} \mathrm{N}\right)$, the Munk layer $(\sim 90 \mathrm{~km})$ is minimally resolved. The effects of mesoscale eddies on temperature and salinity are parameterized by the combination of the isopycnal diffusion and the Gent-McWilliams scheme (Gent and McWilliams, 1990), with coefficients for isopycnal diffusion of tracers and isopycnal thickness of $250 \mathrm{~m}^{2} \mathrm{sec}^{-1}$. Convection in the model is modeled by the implicit scheme of Pacanowski and Griffies (1999).

The surface heat and freshwater fluxes have a form of restoring to the constant values of the sea-surface temperature and salinity, both derived from the observed winter-time climatological values (Levitus and Boyer, 1994), zonally averaged separately within the real Atlantic and Pacific basins. The restoring time scales for temperature and salinity are 60 and 360 days (for a 50-meter mixed layer), respectively. The restoring of temperature corresponds to a highly idealized form of Haney (1971) boundary conditions; weak restoring of salinity is less physically justified and is intended to keep surface density close to a desired profile. A study of the sensitivity of the results to the strength of the restoring will be carried out in Section 4. In order to bring deep temperature closer to the observations, the restoring SST in the Atlantic is decreased by 2 degrees north of the $60^{\circ} \mathrm{N}$, and by 1 degree between $55^{\circ} \mathrm{N}$ and $60^{\circ} \mathrm{N}$. The constant zonal-mean zonal surface wind stress is derived for the Atlantic and Pacific basins separately, from the NCEP 1979-2001 reanalysis. 
In order to keep the deep density values close to the observed values, we choose to mimic heat and salt exchanges between the lower part of the NADW and AABW, by using the following heat and salt fluxes through the bottom boundary of the model:

$$
\begin{aligned}
& F_{\text {heat }}^{\text {bot }}=\frac{k}{\Delta z}\left(T_{b o t}^{*}-T_{b o t}\right) \\
& F_{\text {salt }}^{\text {bot }}=\frac{k}{\Delta z}\left(S_{b o t}^{*}-S_{b o t}\right)
\end{aligned}
$$

where $k$ is $10^{-5} \mathrm{~m}^{2} \mathrm{sec}^{-1}, \Delta z$ is the thickness of the bottom layer, $T_{b o t}^{*}$ and $S_{b o t}^{*}$ are target temperatures (derived from the zonal mean Levitus values at 3000-m depth) and $T_{b o t}$ and $S_{b o t}$ are model-simulated temperature and salinity in the bottom layer.

\section{b. Atlantic-only model}

The Atlantic-only simulations are carried out in a rectangular basin 60-degrees wide and extending from $48^{\circ} \mathrm{S}$ to $64^{\circ} \mathrm{N}$ in the meridional direction. All parameters, surface boundary conditions, the formulation for the bottom fluxes (1) and the size of the Atlantic domain are identical to those in the global simulations.

There is a numerical "sponge layer" in the latitude range $48-47^{\circ} \mathrm{S}$, which is either inactive ("free simulations," Section $3 b$ ) or is used to effectively replace the influence of the entire SO on the Atlantic MOC and stratification. Within the sponge layer, temperature/salinity structure is prescribed at $47.5^{\circ} \mathrm{S}$ to a specified "target profile" taken from the global simulations in Sections 3c, 4a, 4b and 5. The eddy heat/salt fluxes (parameterized by the Gent-McWilliams scheme; "GM fluxes") can also be readily prescribed at $47^{\circ} \mathrm{S}$. The form of the sponge layer used in this study is the most efficient way of controlling stratification at the SO-Atlantic boundary $\left(\sigma_{S}\right)$ and represents a limiting case of a conventional sponge layer with the restoring time scale taken to be infinitely short. The no-flow boundary conditions are used at $48^{\circ} \mathrm{S}$ for the meridional velocities. The velocities are, however, allowed to adjust to the local momentum balance at $47^{\circ} \mathrm{S} .^{3}$

Several experiments have been performed using the hybrid model with the linear equation of state. Surface boundary conditions now have a form of restoring density to the target profile $\sigma_{\theta}^{*}$; the restoring time scale is 60 days, unless noted otherwise. The restoring profile at the surface is chosen to be identical to the density calculated from $T^{*}$ and $S^{*}$ in the standard model. The bottom boundary fluxes (1) are not used. The target profile $\sigma_{S}$ is given by an analytical expression; see Section $4 \mathrm{~b}$. This configuration will be referred to as the "simplified hybrid model."

3. Our attempts to prescribe meridional velocities led to unrealistic and unstable circulation near the southern boundary; the meridional velocities in the vicinity of the boundary are more effectively controlled by the prescribed stratification. Conservation of mass results in strong vertical motions contained entirely within the numerical sponge layer. 


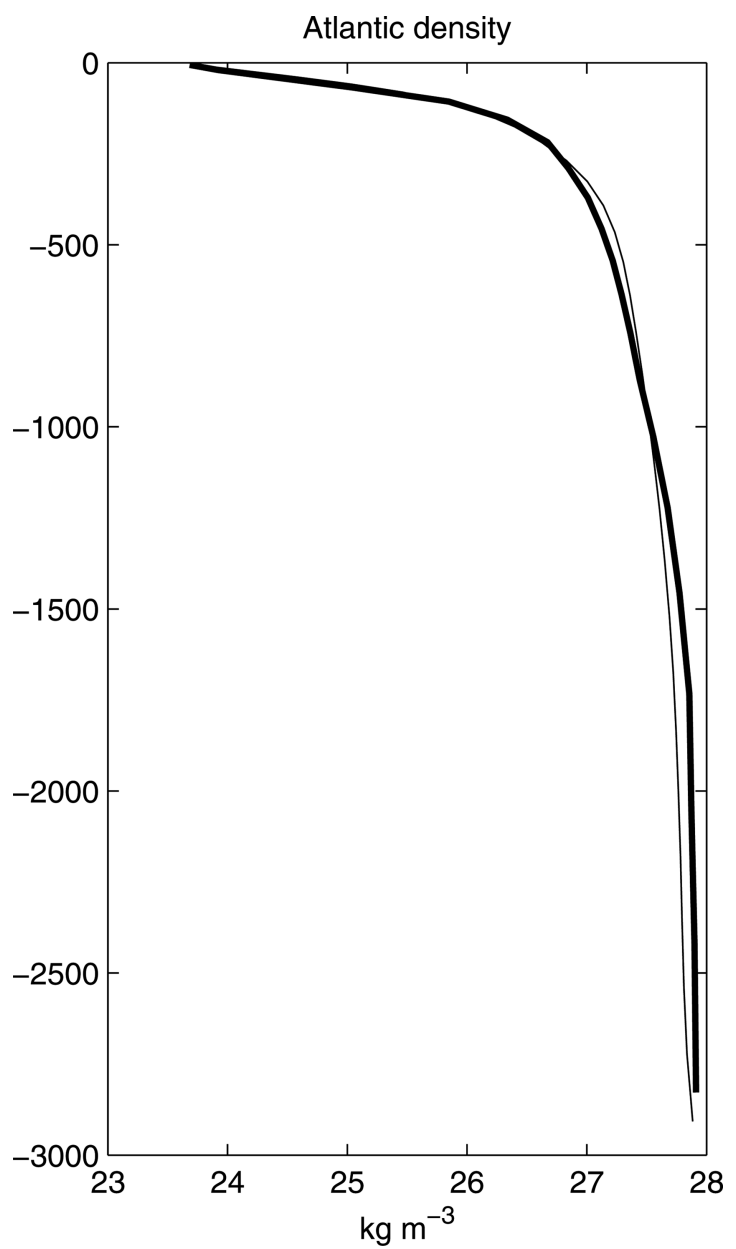

Figure 2. Potential density $\sigma_{\theta}$ (referenced to the surface) in the Atlantic basin, averaged between $20^{\circ} \mathrm{S}$ and $20^{\circ} \mathrm{N}$ : calculated from the Levitus (Levitus and Boyer, 1994) climatology (heavy solid; upper 3000 meters) and simulated by the model (regular solid). Units are $\mathrm{kg} \mathrm{m}^{-3}$.

\section{Importance of SO: Global and Atlantic-only simulations}

\section{a. Global simulations}

The equilibrium stratification in the global run (GLOBAL) is reasonably close to the one calculated from the Levitus data, as is shown in Figure 2. The model pycnocline is, however, somewhat shallower than in the observations. This negative bias in the pycnocline depth could be easily alleviated by higher vertical diffusivity which is, however, not supported by observations. By choosing a low value of vertical diffusivity, we limit the amount of diapycnal mixing to more realistic levels, which is consistent with our focus on nearly isopycnal SO-Atlantic interactions. 
AMOC intensity is conventionally described here through the meridional overturning streamfunction, representing the net meridional volume transport in z-coordinates between the bottom $(z=-D)$ and a given depth level $z$ :

$$
\Psi_{z}(y, z)=\int_{x_{w}}^{x_{e}} d x \int_{-D}^{z} v(x, y, z) d z
$$

or in density coordinates, as an integral between the bottom and the height $Z(x, y, \sigma)$ of a given isopycnal $\sigma$ (potential density referenced to the surface):

$$
\Psi_{\sigma}(y, \sigma)=\int_{x_{w}}^{x_{e}} d x \int_{-D}^{Z(x, y, \sigma)} v(x, y, z) d z,
$$

where $v$ is the meridional velocity, and $x_{w}$ and $x_{e}$ - positions of the western and eastern boundaries. The simulations exhibit vigorous AMOC (Fig. 3a) with the maximum $\Psi_{z}\left(\Psi_{\sigma}\right)$ of $20.2 \mathrm{~Sv}(21.9 \mathrm{~Sv})$ at $51^{\circ} \mathrm{N}$. When the eddy-induced velocities, parameterized by the GentMcWilliams scheme, are added to the actual velocities, the resulting residual streamfunction is very close to $\Psi_{z}$ and the maximum value is $21.4 \mathrm{~Sv}$. The depth $(1600 \mathrm{~m})$ and magnitude of the overturning are roughly consistent with observation-based estimates by Talley et al. (2003). Almost 9 Sv of NADW formed at high latitudes upwell through the isopycnal surfaces and are therefore "short-circuited," primarily in the Northern Hemisphere; the remaining 13.1 Sv of $\Psi_{\sigma}$ exit the Atlantic basin into SO. The meridional circulation in the Pacific basin (Fig. 3b) is substantially weaker; it amounts to only $7.1 \mathrm{~Sv}$ and is located at approximately $40^{\circ} \mathrm{S}$ and a depth of approximately 900 meters. The Pacific overturning cell is significantly shallower than its observational estimates in Talley et al. (2003) - a bias typical for most coarse-resolution GCMs.

The surface separating the northward- and the southward-flowing branches of AMOC referred to as the "no-flow" surface (or $Z_{0}$; see Fig. 1a) is shown by the thick gray dashed line in Figure 3c. This surface is calculated in density space as the density at which the transport reverses and then extrapolated to the $\mathrm{z}$-coordinates to produce $Z_{0}$. In the absence of crossisopycnal volume transport, this surface would correspond to a single density value. Due to cross-isopycnal flow, such as the midlatitude upwelling, the density of the $Z_{0}$ surface varies with latitude. As one moves southward, this surface corresponds to progressively lighter densities, which also indicates an overall decrease in the density of the lower, southwardflowing branch of AMOC, caused by its gradual mixing with the upper, northward-flowing AMOC branch. All isopycnals corresponding to the upper branch outcrop in the SO, with the isopycnals in the range of $\sigma_{\theta}=26.7-27.2$ outcropping in the "supergyre region" in the latitude range $55-47^{\circ} \mathrm{S}$. Very dense layers that outcrop south of the ACC latitudes in nature do not surface in the model Southern Hemisphere. The net zonal transport in ACC is $169 \mathrm{~Sv}$. The Pacific isopycnals are on average deeper than in the Atlantic. 
a) Atlantic

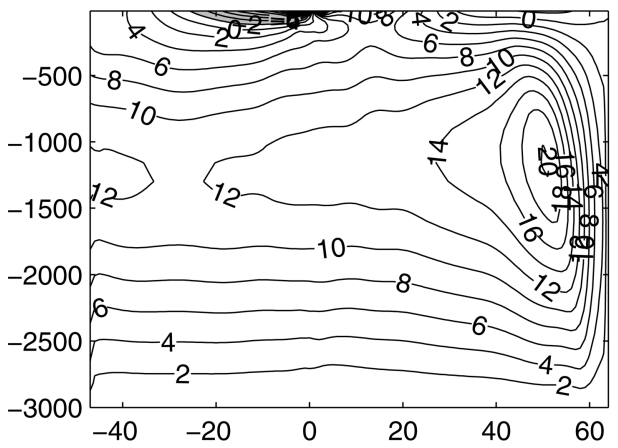

c) Atlantic

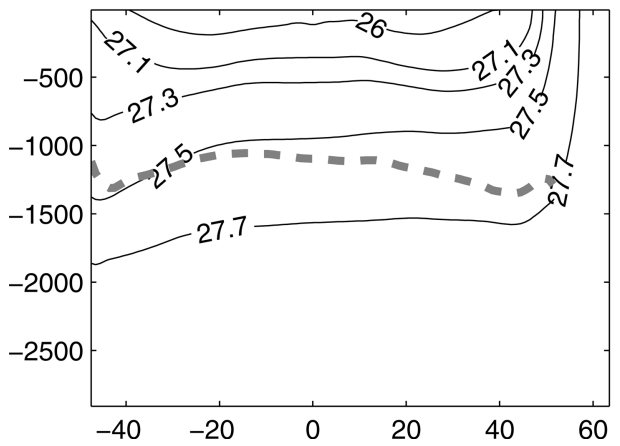

b) Pacific

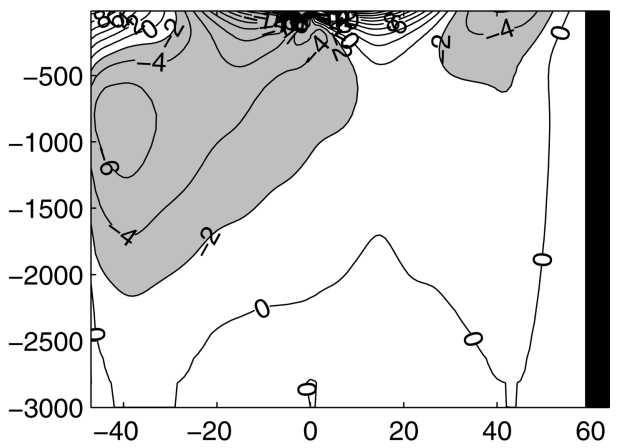

d) Pacific

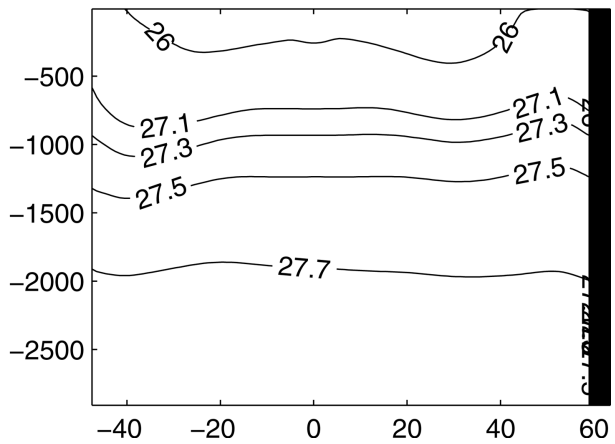

Figure 3. MOC and stratification in the GLOBAL simulation. Upper row shows the meridional overturning streamfunction (z-coordinate) $\Psi_{z}$ as a function of latitude and depth (in Sv) for the (a) Atlantic and (b) Pacific basins. Negative values (sinking in the south) are shaded. Bottom row shows zonally averaged potential density anomaly $\sigma_{\theta}$ (referenced to the surface) for the (c) Atlantic and (d) Pacific basins. Zonally averaged position of the $Z_{0}$ surface, which separates the northwardand southward-flowing branches of AMOC, is shown by the thick gray line.

\section{b. Atlantic-only "free" simulation}

This is the conventional Atlantic-only setting (ATL_Free) routinely used in single-basin simulations of the AMOC; the sponge layer is not activated. Consistent with the earlier results (e.g. Bryan, 1987; Klinger and Marotzke, 1999; Wolfe and Cessi, 2010), the resulting overturning (Fig. 4a) is weak with maximum $\Psi_{z}=7.6 \mathrm{~Sv}$ and $\Psi_{\sigma}=8.2 \mathrm{~Sv}$. Unrealistically high levels of diapycnal mixing of $0.5-1.0 \times 10^{-4} \mathrm{~m}^{2} \mathrm{sec}^{-1}$ would be needed to bring AMOC to a more realistic strength of approximately $20 \mathrm{~Sv}$. The $Z_{0}$ surface in the Northern Hemisphere (Fig. 4c) corresponds to $\sigma_{\theta}=27.6-27.8$ - very similar to the range observed in the global model $\left(\sigma_{\theta}=27.55-27.7\right)$. The isopycnals are shallow, but the mid-depth deep stratification is weak.

Similar to the AMOC in GLOBAL, the upwelling in ATL_Free is contained primarily in the Northern Hemisphere but is weaker. For example, the net diapycnal flux through 
a) AMOC in the ATL Free

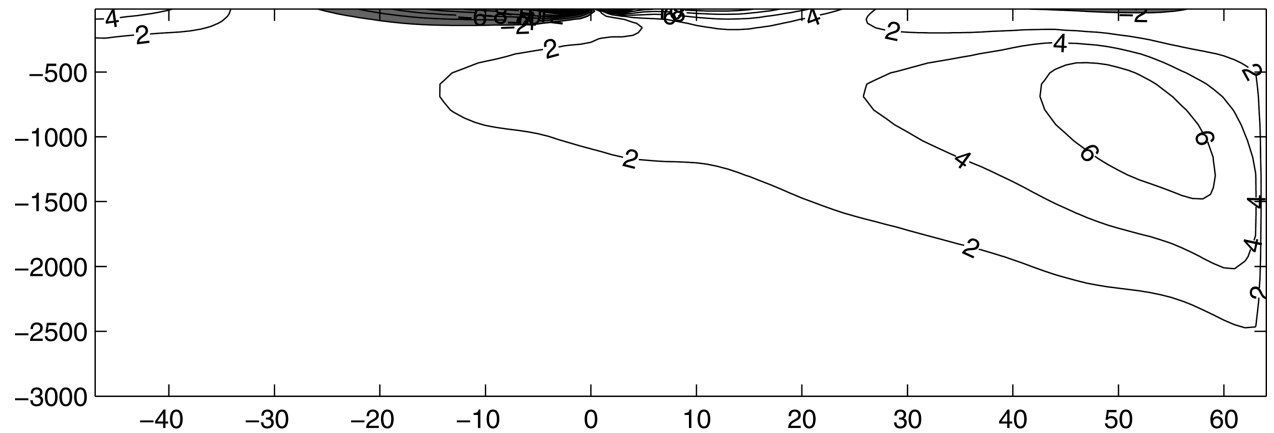

b) Stratification in ATL Free

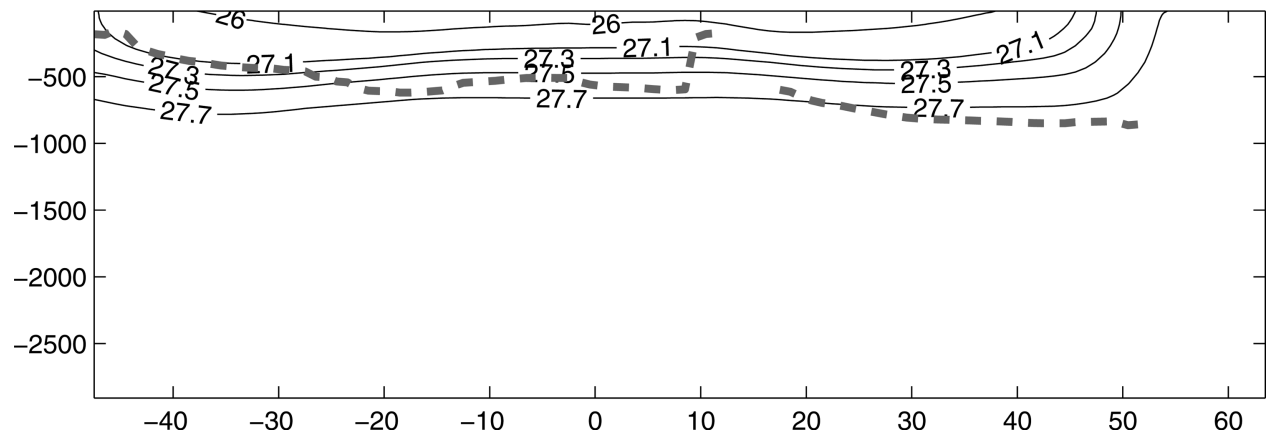

Figure 4. MOC and stratification in the free Atlantic-only (ATL_Free) simulation. Upper panel shows the meridional overturning streamfunction (z-coordinate) $\Psi_{z}$ as a function of latitude and depth (in $\mathrm{Sv}$ ). Negative values (sinking in the south) are shaded. Bottom panel shows zonally averaged potential density anomaly $\sigma_{\theta}$ (referenced to the surface). Zonally averaged position of the $Z_{0}$ surface, which separates the northward- and southward-flowing branches of AMOC, is shown by the thick dashed line. Note a significantly weaker circulation and shallower stratification than in GLOBAL.

the $Z_{0}$ surface in the Northern Hemisphere (between the Equator and $51^{\circ} \mathrm{N}$ ) is $3.8 \mathrm{~Sv}$ in ATL_Free and $4.3 \mathrm{~Sv}$ in GLOBAL. The upwelling is not uniform. Most of this upwelling takes place within approximately 2 degrees of the western boundary and is partly compensated by the interior downwelling. This is similar to Marotzke and Klinger (2000) who employed boundary-intensified diapycnal mixing. In the z-coordinates, the western boundary upwelling in the Northern hemisphere reaches a maximum of approximately $14 \mathrm{~Sv}$ (at $900 \mathrm{~m}$ ) for the GLOBAL and $7 \mathrm{~Sv}$ (at $500 \mathrm{~m}$ ) for ATL_Free. Note that weaker upwelling and tighter stratification in ATL_Free are inconsistent with a popular scaling for the interior upwelling velocity $W$ that is derived from the one-dimensional advective-diffusive balance: $W \sim k_{v} / D$, where $D$ is the characteristic pycnocline depth. It is conceivable that this is a result of the small explicit vertical diffusivity in the model. We revisit the dependence of upwelling on stratification in Section $4 \mathrm{~b}$. 
Table 1. Sensitivity experiments and their main characteristics. The following AMOC properties are given: maximum $\Psi_{\mathrm{z}}$ values (and the values with GM velocities added, $\Psi_{z}^{r e s}$ ), as well $\Psi_{\mathrm{z}}$ and $\Psi_{\sigma}$ values at $47 \mathrm{~S}$.

\begin{tabular}{|c|c|c|c|c|c|}
\hline & Geometry & $\begin{array}{l}\text { Southern } \\
\text { boundary }\end{array}$ & Other & $\begin{array}{c}\operatorname{Max} \Psi_{\mathrm{z}} \\
\left(\Psi_{z}^{\text {res }}\right)\end{array}$ & $\begin{array}{c}\Psi_{Z}\left(\Psi_{\sigma}\right) \\
\text { at } 47 \mathrm{~S}\end{array}$ \\
\hline GLOBAL & global & N/A & & $\begin{array}{c}20.2 \mathrm{~Sv} \\
(21.4 \mathrm{~Sv})\end{array}$ & $\begin{array}{c}12.3 \mathrm{~Sv} \\
(13.1 \mathrm{~Sv})\end{array}$ \\
\hline ATL_Free & Atlantic & none & & $\begin{array}{c}7.6 \mathrm{~Sv} \\
(9.5 \mathrm{~Sv})\end{array}$ & 0 \\
\hline ATL2D & Atlantic & $\begin{array}{l}\text { 2D T/S, } \\
\text { GM fluxes }\end{array}$ & & $\begin{array}{c}20.4 \mathrm{~Sv} \\
(21.8 \mathrm{~Sv})\end{array}$ & $\begin{array}{c}12.3 \mathrm{~Sv} \\
(11.9 \mathrm{~Sv})\end{array}$ \\
\hline ATL1D & Atlantic & $\begin{array}{l}\text { Zonal- } \\
\text { mean T/S }\end{array}$ & & $\begin{array}{c}19 \mathrm{~Sv} \\
(20.1 \mathrm{~Sv})\end{array}$ & $\begin{array}{l}9.8 \mathrm{~Sv} \\
(9.7 \mathrm{~Sv})\end{array}$ \\
\hline ATL1D_Pac & Atlantic & $\begin{array}{l}\text { Zonal- } \\
\text { mean T/S }\end{array}$ & $\begin{array}{l}\mathrm{T} / \mathrm{S} \text { from } \\
\text { Pacific }\end{array}$ & $\begin{array}{c}20.7 \mathrm{~Sv} \\
(21.8 \mathrm{~Sv})\end{array}$ & $\begin{array}{c}10.7 \mathrm{~Sv} \\
(10.7 \mathrm{~Sv})\end{array}$ \\
\hline ATL2D_SW & Atlantic & $2 \mathrm{D} \mathrm{T} / \mathrm{S}$ & $\begin{array}{l}\text { Reduced } \\
\text { SH winds }\end{array}$ & $\begin{array}{c}20.5 \mathrm{~Sv} \\
(20.7 \mathrm{~Sv})\end{array}$ & $\begin{array}{c}12.3 \mathrm{~Sv} \\
(12.2 \mathrm{~Sv})\end{array}$ \\
\hline ATL2D_GM & Atlantic & $2 \mathrm{D} \mathrm{T} / \mathrm{S}$ & $\begin{array}{l}\text { Reduced } \\
\text { GM }\end{array}$ & $\begin{array}{c}20.5 \mathrm{~Sv} \\
(20.5 \mathrm{~Sv})\end{array}$ & $\begin{array}{l}11.2 \mathrm{~Sv} \\
(10.9 \mathrm{~Sv})\end{array}$ \\
\hline GLOBAL_AN & global & N/A & $\begin{array}{l}\text { NA SSS } \\
\text { anomaly }\end{array}$ & $\begin{array}{c}16.0 \mathrm{~Sv} \\
(17.3 \mathrm{~Sv})\end{array}$ & $\begin{array}{l}9.8 \mathrm{~Sv} \\
(11 S v)\end{array}$ \\
\hline ATL2D_AN & Atlantic & $2 \mathrm{D} \mathrm{T} / \mathrm{S}$ & $\begin{array}{l}\text { NA SSS } \\
\text { anomaly }\end{array}$ & $\begin{array}{c}11.5 \mathrm{~Sv} \\
(12.5 \mathrm{~Sv})\end{array}$ & $\begin{array}{c}6.2 \mathrm{~Sv} \\
(6.15 \mathrm{~Sv})\end{array}$ \\
\hline
\end{tabular}

\section{c. Simulations with the hybrid model}

The results demonstrate that the prescribed southern stratification effectively replaces the Southern Ocean in its influence on the AMOC and Atlantic stratification; thus the term "hybrid model." We show here the results from the simulation with prescribed stratification only ("ATL2D"); as is discussed in Section 5a, the parameterized eddy fluxes have very little influence on the results in this study. Northward of $46^{\circ} \mathrm{S}$, the AMOC and mean stratification are very similar to the ones in the global simulations. In particular, the AMOC intensity reaches a maximum of $20.4 \mathrm{~Sv}$ at $51^{\circ} \mathrm{N}(20.2 \mathrm{~Sv}$ in GLOBAL); see Table 1 and Figure 5a. The isopycnals in ATL2D and GLOBAL are very close to each other, especially at the depths above the no-flow surface $Z_{0}$ (Fig. 5c). The isopycnal AMOC $\Psi_{\sigma}$ is very similar between the two cases. Note also that the prescription of the southern density significantly deepens the isopycnals in ATL2D compared to ATL_Free, which results in a much stronger AMOC in the former case.

This hybrid model, therefore, represents a convenient tool for this study and allows a detailed analysis of the importance of several processes in the vicinity of the SO-Atlanic boundary. In particular, the southern stratification and other factors can be readily varied in a sensitivity study aimed at identifying main factors that determine the Atlantic stratification and MOC. 
a) AMOC: ATL2D

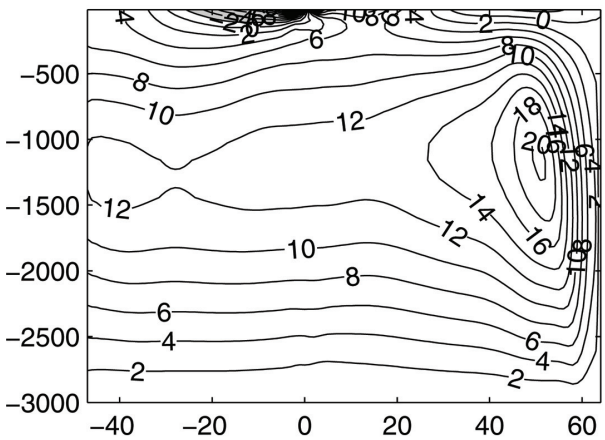

c) Zonal-mean stratification

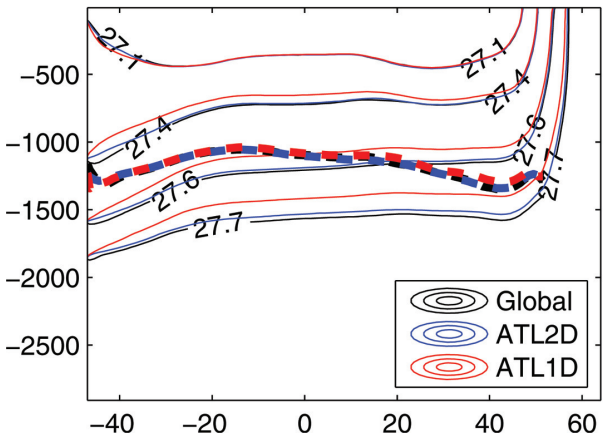

b) AMOC: ATL1D

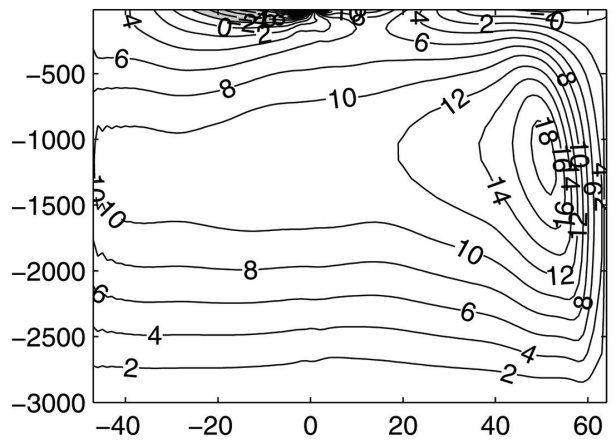

d) SO stratification

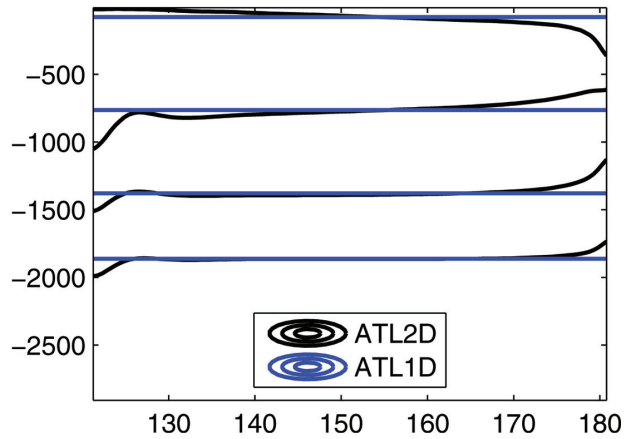

Figure 5. MOC and stratification in the hybrid Atlantic-only simulations. Upper row shows the Atlantic meridional overturning streamfunction (z-coordinate) $\Psi_{z}$ as a function of latitude and depth (in Sv) for the (a) ATL2D and (b) ATL1D simulations. Negative values (sinking in the south) are shaded. Panel (c) shows zonally averaged potential density anomaly $\sigma_{\theta}$ (referenced to the surface) in the Atlantic for the GLOBAL, ATL2D and ATL1D simulations. Zonally averaged position of the $Z_{0}$ surface, which separates the northward- and southward-flowing branches of AMOC, is shown by the thick dashed lines. Panel (d) shows $\sigma_{S}$ (47.5S) in ATL2D and ATL1D simulations as functions of depth and longitude.

\section{Influence of the SO stratification on AMOC}

The foregoing calculations suggest the primary importance of the southern stratification $\sigma_{S}(\mathrm{x}, \mathrm{z})$ in shaping the Atlantic stratification and MOC. The following analysis attempts to specify the characteristics of stratification that are particularly significant in this regard. Specifically, we will address the importance of zonal density variation within the Atlantic sector of SO (Section 4a), examine the sensitivity to the depth of $\sigma_{S}$ isopycnals in a suite of idealized simulations (Section 4b) and offer physical explanation of this sensitivity in Section $4 c$. 


\section{a. Significance of the zonal density gradient within the Atlantic sector}

The southern boundary of our Atlantic-only domain is placed at the latitude of the northern flank of the "supergyre" region of SO $\left(55-47^{\circ} \mathrm{S}\right)$, where the meridional circulation is determined by the geostrophic balance. The prescribed two-dimensional temperature/salinity structure thus imposes a strong control on the meridional geostrophic velocities and volume/buoyancy exchanges across the SO-Atlantic boundary. Thus, at first, the similarity in AMOC between the GLOBAL and ATL2D simulations seems very natural. A more systematic analysis reveals an intricate mechanics of the AMOC control by the SO stratification.

In a new sensitivity experiment ATL1D, the sponge-layer values of temperature and salinity are independent of longitude and prescribed to their zonally averaged values in GLOBAL; ${ }^{4}$ the meridional diffusive heat/salt fluxes at $47^{\circ} \mathrm{S}$ are set to zero (as in experiment ATL2D). There is, therefore, no direct control of the zonal gradients in $\sigma_{S}$ on the meridional geostrophic currents into the Atlantic. In the latitudes immediately north of the sponge layer, the density is, however, free to adjust its zonal structure and develop zonal gradients and meridional geostrophic currents. In fact, the meridional currents everywhere north of the sponge layer are very similar between the two experiments. AMOC intensity in ATL1D is only about $1.5 \mathrm{~Sv}$ weaker than in ATL2D and is still significantly stronger than in ATL_Free: the maximum $\Psi_{z}$ in the Northern Hemisphere is $19 \mathrm{~Sv}$. The differences in the isopycnal overturning between ATL1D and ATL2D are even less significant (less than $1 \mathrm{~Sv}$; not shown).

The differences in deep stratification are equally small. In particular, the deep zonal-mean isopycnals are slightly shallower in ATL1D compared to ATL2D (Fig. 5c). To interpret this difference, a close look at the three-dimensional density structure is required. Zonally uniform $\sigma_{S}$ isopycnals in ATL1D are shallower than the $\sigma_{S}$ isopycnals in ATL2D near the western boundary and deeper near the eastern wall (Fig. 5d). The fact that the deep (below $1000 \mathrm{~m}$ ) stratification is shallower in ATL1D than in ATL2D is then the first indication of the importance of the western stratification, which is further explored and interpreted in the rest of Section 4.

Despite the small differences in AMOC and density structure, it is clear, that the isopycnal depth at the SO-Atlantic boundary is a key parameter influencing the Atlantic stratification and MOC from the south. Surprisingly, the presence of the zonal density gradients in $\sigma_{S}$ does not play any significant role.

\section{b. Sensitivity to the depth of $\sigma_{S}$ isopycnals in the simplified hybrid model}

The dependence of the upper AMOC and Atlantic stratification on the SO isopycnal depth is systematically investigated in a sensitivity study of this section. To make the analysis most straightforward, it is carried out in a simplified version of the hybrid model, which employs

4. Despite the nonlinearity of the equation of state, the resulting density at $47.5^{\circ} \mathrm{S}$ is nearly identical to the zonal-mean density in OA2D. 
a linear equation of state. The southern density profile prescribed at the southern boundary of the Atlantic domain is chosen to be a linear function of depth only:

$$
\sigma_{S}(z)=\sigma_{S}(0)(1-C Z / d)
$$

where $c=0.0265$ and the SO stratification can be easily varied using a single parameter the depth scale $d$. A suite of sensitivity experiments are conducted for six different values of the depth scale $d$, with large values corresponding to deeper SO isopycnals.

Stratification is highly sensitive to changes in $\sigma_{S}$. Figure 6a illustrates the position of isopycnals at the western $\left(\sigma_{w}\right)$ and eastern $\left(\sigma_{e}\right)$ walls for two runs, one with a large $(2500 \mathrm{~m})$ and one with a smaller value $(1520 \mathrm{~m})$ of $d$. Due to the geostrophic constraints at the eastern wall, the eastern isopycnals are flat in most of the domain, with the exception of the southernmost and northernmost regions, characterized by upwelling/downwelling and active convection. In the deep ocean, the zonal gradient $\Delta \sigma=\sigma_{w}-\sigma_{e}$ is zero at the equator, since the net meridional current does not change direction across the equator (Marotzke and Klinger, 2000). Because of this structure, $\sigma_{e}$ (and $\Delta \sigma$ ) are strongly controlled by the orientation of $\sigma_{w}$ isopycnals. In particular, the meridional slope of those western isopycnals that are within the range of $\sigma_{S}$ and outcrop in the Northern Hemisphere increases with larger $d$. This is in large part explained by the nearly fixed density structure at the surface - and outcrop positions of the $\sigma_{w}$ isopycnals - in these runs. The upper-ocean isopycnal layers ventilated from the sea-surface within the Atlantic basin from the south and north, in contrast, appear to be largely insensitive to changes in $\sigma_{S}$ (Fig. 6a).

As expected, the AMOC strength increases with the vertical scale $d$. The dependence is nearly quadratic at the Equator (Fig. 7), which is in close agreement with previous scaling assumptions (e.g., Gnanadesikan, 1999) and results by Wolfe and Cessi (2010). In the next section we interpret this dependence using a scaling based on the observed sensitivity of the density structure in our simulations. In contrast, the dependence of the AMOC maximum in the North Atlantic on $d$ is weaker and is nearly linear. This difference between the response of the low and high latitudes is explained by the presence of upwelling near the western boundary, which "short-circuits" a portion of MOC north of the Equator and increases with larger $d$. This vertical volume flux is fed by the zonal flow toward the western boundary, in turn supported by the meridional pressure gradient near the western wall. In accord with the increasing slope of the $\sigma_{w}$ isopycnals, the vertical volume flux within the western boundary (not shown) increases with the depth scale $d$.

How important is the position of the isopycnal outcrop in the North Atlantic, constrained in this study, for the strong sensitivity of AMOC to $d$ ? Although the answer to this question calls for coupled simulations with active atmosphere-ocean feedbacks, not feasible in this study, we can assess the importance of the outcrop position by increasing the restoring time scale from 60 to 180 days. These changes result in a weaker overturning (Fig. 7), and somewhat weaker dependence of AMOC on $d$. The latter fact is explained by larger departures of surface density values from the surface restoring profile, which weakens the dependence of the isopycnal orientation on $\sigma_{S}$; see further discussion in the next Section. 
a) Western and Eastern stratification

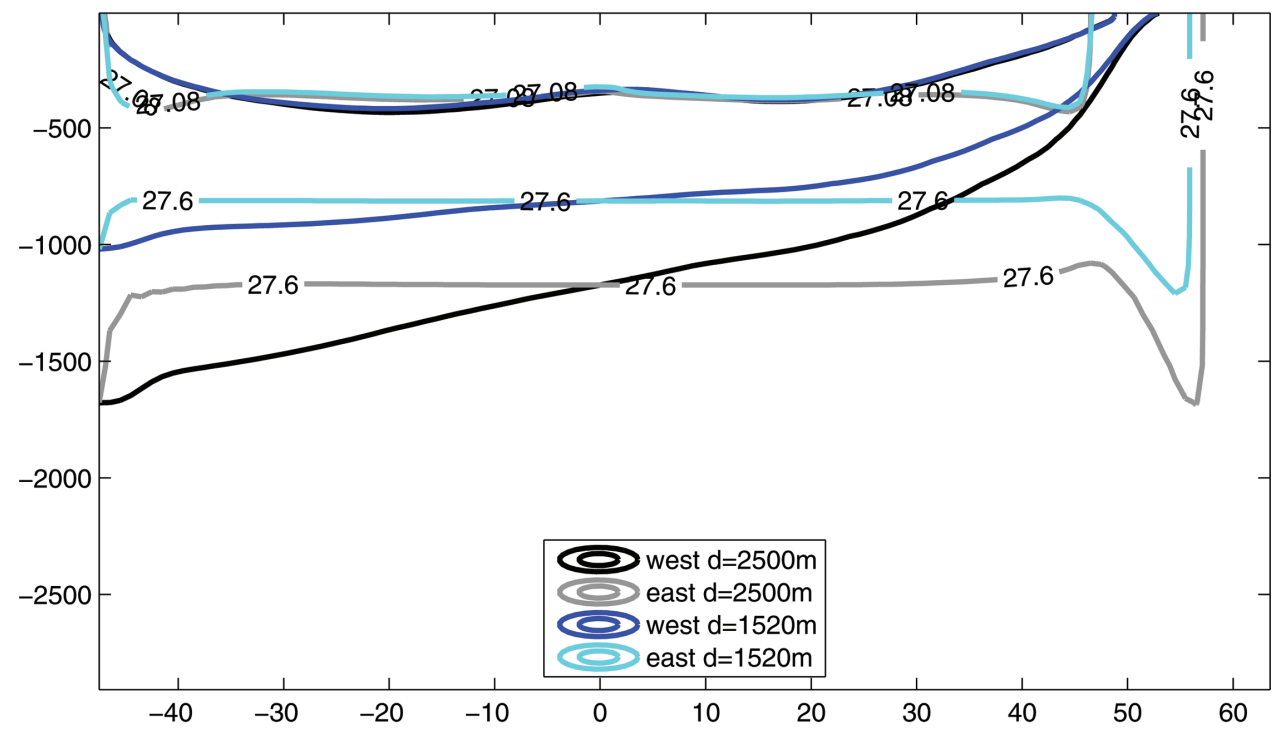

b) Zonal-mean stratification

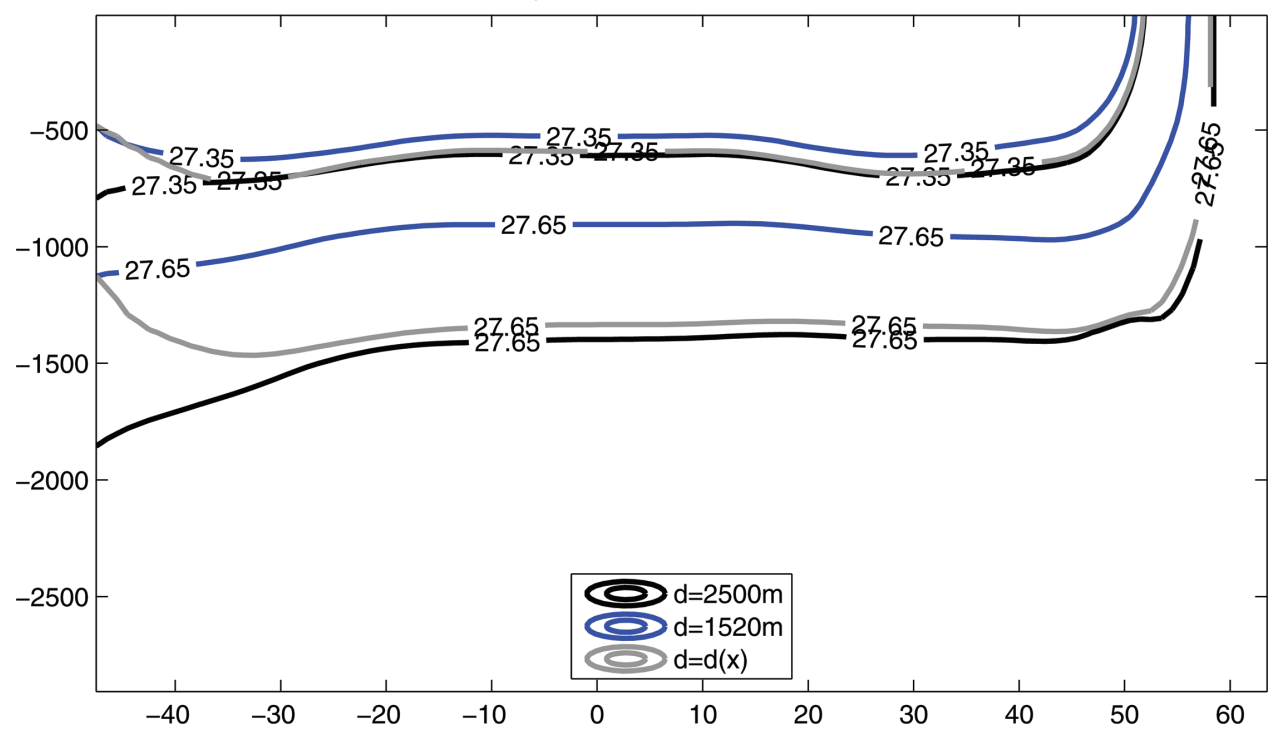

Figure 6. Dependence of the stratification on the depth scale $d$. (a) Stratification at the western $\left(\sigma_{w}\right.$, black and blue) and eastern ( $\sigma_{e}$, grey and cyan) wall and their dependence on the southern density $\sigma_{S}$. Isopycnal positions are shown for $\sigma=27.08$ and 27.6 and for two values of $d: 2500$ and 1520 meters. Note the strong meridional slope of the deep $\sigma_{w}$ isopycnals, nearly horizontal orientation of the deep $\sigma_{e}$ isopycnals and the lack of sensitivity of the shallow isopycnals ("ventilated thermocline") to the vertical scale $d$. (b) Zonal-mean stratification for $\sigma=27.35$ and 27.65 and for three values of $d: 2500 \mathrm{~m}$ (black), $1520 \mathrm{~m}$ (blue) and longitude dependent (gray; see text). 


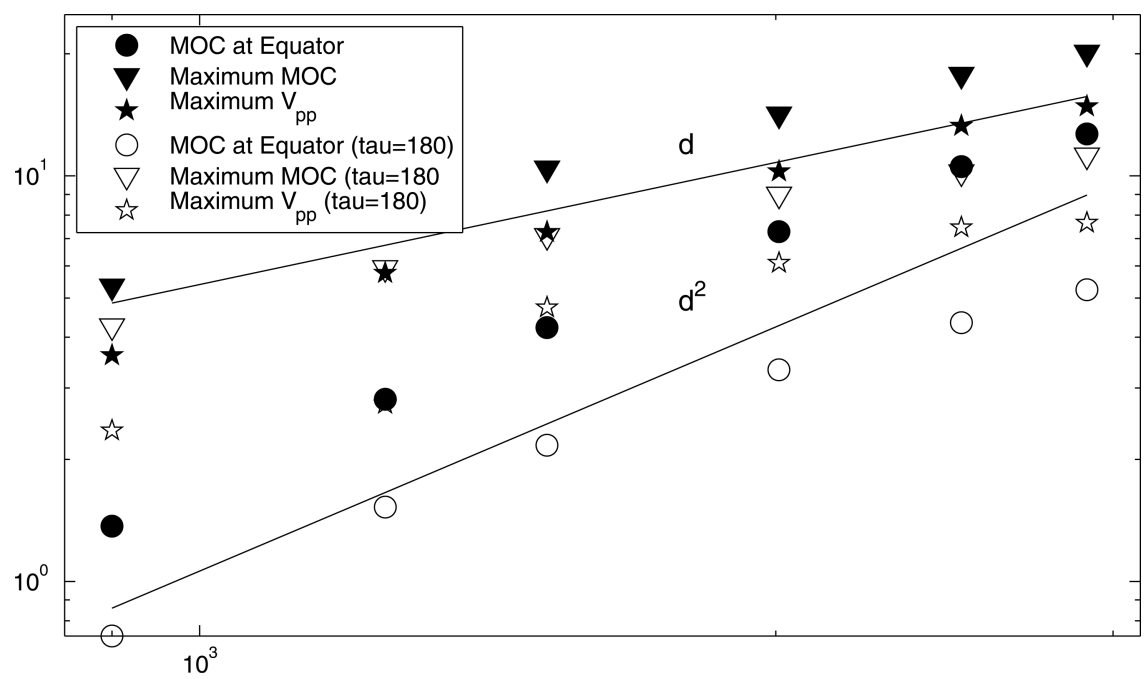

Figure 7. Sensitivity of AMOC to SO stratification in idealized sensitivity studies. Three measures of the AMOC strength, the maximum overturning in the North Atlantic (triangles), isopycnal overturning at the Equator (circles) and maximum in the push-pull mode strength ( $V_{p p}$, stars) are shown on the logarithmic scale as functions of the vertical scale $d$, together with the lines $d$ and $d^{2}$ (shifted for presentation purposes). Values for the standard runs are shown by the filled markers, values for the runs with the restoring scale of 180 days - by open markers. Units are Sverdrups.

The overall sensitivity of AMOC to $d$, however, remains strong and qualitatively similar to that in the standard case.

How important is the restriction of the domain depth to 3000 meters for the reported sensitivity to $d$ ? To address this question, the domain depth is increased to 4500 meters and two simulations, one with $d=2500 \mathrm{~m}$ and one with $d=2000 \mathrm{~m}$ were carried out. The largest difference with standard simulations is in the deep ocean. The most important change is the formation of a bottom MOC cell, characterized by downwelling in the south and upwelling in the north; this is the model analog of AABW. The upper AMOC cell is, however, only weakly affected, which is consistent with the findings by Kamenkovich and Goodman (2000). Its maximum strength in the 3000-meter and 4500-meter deep simulations is very similar: $17.8 \mathrm{~Sv}(3000 \mathrm{~m})$ and $18.9 \mathrm{~Sv}(4500 \mathrm{~m})$ for $d=2500 \mathrm{~m}$ and $14.2 \mathrm{~Sv}(3000 \mathrm{~m})$ and $14.7 \mathrm{~Sv}(4500 \mathrm{~m})$ for $d=2000 \mathrm{~m}$.

\section{c. Physical interpretation of the results: importance of the western stratification}

The observed sensitivity of the western/eastern stratification to varying the depth of $\sigma_{S}$ isopycnals suggests the following physical interpretation of the processes involved in the SO control on the Atlantic stratification and MOC. The pressure difference $\Delta p$ between the western $\left(p_{w}\right)$ and eastern $\left(p_{e}\right)$ boundaries controls the net meridional geostrophic 
circulation. The impact of varying $\sigma_{S}$ is most profound at the western boundary, where it controls the slope of the $\sigma_{w}$ isopycnals. The $\sigma_{e}$ isopycnals, in contrast, appear to be less sensitive to $\sigma_{S}$. The shoaling (deepening) of the southern isopycnals at the western boundary decreases (increases) the slope of the $\sigma_{w}$ isopycnals (Fig. 6a). These changes can be expected to result in a nearly quadratic dependence of the AMOC strength on the depth scale $d$; see Appendix B.

Why is the western region so important in linking the SO and the Atlantic, but the eastern region seems to passively adjust to the orientation of $\sigma_{w}$ ? The advective mechanism for communication at the western wall, such as the potential vorticity advection, has to be dismissed due to the southward direction of the western boundary currents at the southernmost latitudes. The importance of the western region should, instead, be attributed to the Kelvin wave dynamics, which propagate northward at the western wall and southward at the eastern wall in the Southern Hemisphere. The Kelvin waves, thus, provide an efficient way of controlling the western Atlantic stratification by SO.

This mechanism is missing at the eastern wall, and the eastern part of $\sigma_{S}$ is effectively "detached" from the $\sigma_{e}$, as manifested by an abrupt change in density at the south-eastern corner in Figure 6a. The dynamical "detachment" of the eastern portion of $\sigma_{S}$ from the rest of the Atlantic is also an expected consequence of the geostrophic dynamics, which requires any change in $\sigma_{e}$ to be distributed uniformly along the entire eastern wall - a strong constraint that does not arise near the western boundary due to substantial ageostrophic effects. The requirement of the zero zonal density gradient at the equator (Section $4 b$ ) further ties western and eastern isopycnals together. Since the eastern stratification only weakly responds to the $\mathrm{SO}$ forcing, the changes in mean stratification are associated largely with the changes in the western Atlantic.

To confirm this interpretation, we carry out an additional sensitivity experiment intended to answer the following question: Is AMOC controlled by the $\sigma_{S}$ in the west or by the zonal-mean southern stratification? In this experiment, $d$ in (4) is the linear function of longitude, changing from 2500 meters at the western wall to 1520 meters in the middle of the basin. The zonal-mean value of $\sigma_{S}$ in this case is then the same as $\sigma_{S}$ given by (4) with $d=1520 \mathrm{~m}$. The resulting maximum AMOC $\left(\Psi_{z}\right)$ is almost $17 \mathrm{~Sv}$ which is very close to its value when $d$ is constant and equal to 2500 meters $(17.8 \mathrm{~Sv})$, but much stronger than in the case with $d=1520 \mathrm{~m}(10.4 \mathrm{~Sv})$. Zonally averaged stratification in this experiment is very similar to the one in the simulation with $d=2500 \mathrm{~m}$ north of approximately $30 \mathrm{~S}$ (Fig. 6b); southward of this latitude, the mean stratification approached a value in the simulation with $d=1520 \mathrm{~m}$. The western part of the SO stratification is clearly the key parameter controlling AMOC and stratification.

An experiment with $d$ decreasing away from the western boundary was also carried out with longer restoring scale (180 days) and deeper basin (4500 meters). In all these experiments, the resulting maximum AMOC $\left(\Psi_{z}\right)$ in variable and constant $d$ are very close to each other. For the restoring scale of 180 days, it is $10.2 \mathrm{~Sv}$ for $d=2500 \mathrm{~m}$ and $10 \mathrm{~Sv}$ for $d$ changing from 2500 (west) to 1520 (middle) meters. For the 4500-meter domain, 
maximum overturning is $18.9 \mathrm{~Sv}$ for $d=2500 \mathrm{~m}$ and $18.8 \mathrm{~Sv}$ for $d$ changing from 2500 to 2000 meters. These simulations, therefore, demonstrate that the primary importance of the western stratification is a robust property of AMOC.

To further interpret the changes in the AMOC, in the context of changes in stratification in this and the following sections, it is convenient to apply the push-pull conjecture developed by Radko et al. (2008). The push-pull mode is the component of AMOC directly forced by surface buoyancy fluxes and equivalent to the isopycnal AMOC in the absence of the diapycnal fluxes in the oceanic interior below the mixed layer; see Appendix A. Although the actual MOC and its push-pull component can be quite different, Radko et al. (2008) suggested that the push-pull mode can most closely be matched with the isopycnal overturning at the equator.

In agreement with the isopycnal overturning at the Equator, the maximum in the pushpull mode increases with $d$ (Fig. 7) and shifts to heavier densities. In particular, the density $\sigma_{m}$ corresponding to this maximum in the push-pull mode increases from 27.47 to 27.53. Gradual shift to heavier densities, combined with changes in the surface density structure, result in the increase in the surface buoyancy fluxes. These changes are directly linked to the intensification in the push-pull mode with larger $d$. The important conclusion is that the stratification at the SO-Atlantic boundary can determine the buoyancy input at the outcrop of the $Z_{0}$ surface in the North Atlantic.

\section{Sensitivity of MOC and stratification to other factors}

This section quantifies the importance of several factors - Ekman transport, eddy (GMparameterized) exchanges across the SO-Atlantic boundary and the North Atlantic density and compares it with the impact of the prescribed stratification at the SO-Atlantic boundary. Such analysis is generally not straightforward, since the SO stratification is itself influenced by these exchanges and the North Atlantic stratification. To make progress in unraveling these dynamical links, we first isolate direct effects of Ekman and eddy fluxes in simulations with fixed $\sigma_{S}$, and demonstrate their secondary importance (Sections 5a-b). We then analyze the interplay between the southern and northern stratifications (Sections 5c-d). These experiments represent modified versions of our base simulation ATL2D in Section 3b.

\section{a. Eddy-induced transport}

This section is focused on heat/salt exchanges across the SO-Atlantic boundary, due to (parameterized) eddies. Kamenkovich and Sarachik (2004) have demonstrated that the eddy fluxes in SO effectively control the AMOC strength, with the eddy fluxes in the Northern Hemisphere playing a secondary role. The importance of these eddy-driven exchanges across the SO-Atlantic boundary is, however, two-fold: they determine the $\sigma_{S}$ and supply/remove buoyancy to/from the Atlantic. In this section, we examine the importance of the latter, direct effects of eddy fluxes. 


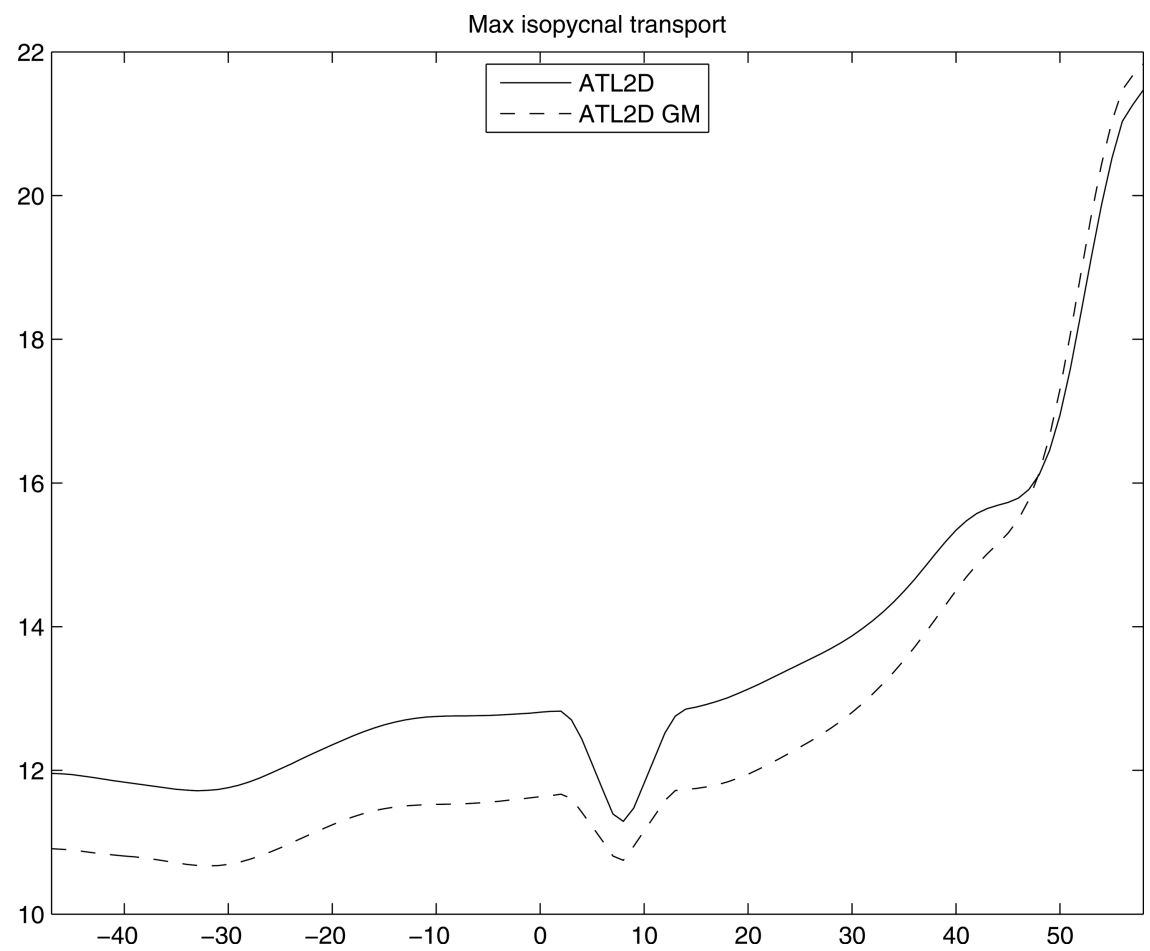

Figure 8. Importance of the parameterized eddy transports (GM fluxes). Shown is the maximum isopycnal MOC $\left(\Psi_{\sigma}\right)$ as a function of latitude for ATL2D (solid) and ATL2D_GM (dashed).

Comparison of ATL2D and the same experiment, but with the GM eddy fluxes prescribed at $47^{\circ} \mathrm{S}$, reveals nearly identical Atlantic states (not shown). In particular, both the AMOC intensity and stratification are nearly the same in both simulations. The above result is not, however, surprising, given the fact that the eddy fluxes in this study are parameterized by the GM scheme, which determines the eddy heat/salt fluxes from the local stratification. The values of these fluxes at $47^{\circ} \mathrm{S}$ in ATL2D, therefore, have to be very close to those in GLOBAL, given that the density structure in both simulations is also very similar.

In order to examine the importance of the GM eddy heat/salt fluxes in this study with the fixed $\sigma_{S}$, a sensitivity experiment ATL2D_GM has been carried out, in which the GM isopycnal-thickness diffusivity is set to a very small value $\left(25 \mathrm{~m}^{2} \mathrm{sec}^{-1}\right)$ in the Atlantic basin; the isopycnal diffusivity is identical in all simulations. The stratification in the sponge layer in ATL2D_SW is prescribed to the same values as in ATL2D. The resulting change in the strength of AMOC is small. Both isopycnal $\Psi_{\sigma}$ (Fig. 8) and z-coordinate $\Psi_{z}$ AMOC are reduced by approximately $1 \mathrm{~Sv}$ in most of the domain. In the North Atlantic, the maximum AMOC transport is practically unchanged (Table 1). The mean depth of isopycnals and the position of the no-flow surface are almost identical to those in ATL2D. This result strongly suggests that the role of eddy transfer in shaping the Atlantic MOC, as previously 
demonstrated by Kamenkovich and Sarachik (2004), is limited to setting the stratification in the SO, especially at its northern flank.

\section{b. Ekman transport}

The objective of this subsection is to isolate and analyze the importance of the meridional Ekman transport of water from SO into the Atlantic. Southern winds play a central role in determining the SO stratification, as demonstrated by many theoretical and numerical studies (see Introduction), and therefore strongly influence AMOC through the position of isopycnals at the SO-Atlantic boundary. In our experiments, these important effects are effectively incorporated into $\sigma_{S}$. This section examines direct effects of local Ekman flux at the SO-Atlantic boundary. It is tempting to interpret the sensitivity of AMOC to southern winds as being caused by the direct contribution of the Ekman volume transport into MOC in the entire Atlantic basin, including the Northern Hemisphere. As will be demonstrated in this section, this contribution, however, is very modest and is limited to the southernmost latitudes of the Atlantic basin.

In the sensitivity experiment ATL2D_SW, the zonal wind stress in the Southern Hemisphere is modified to have a nearly zero magnitude at $47^{\circ} \mathrm{S}$, but smoothly increases to the standard magnitude northward of the Equator (Fig. 9a). The Ekman volume transport in the Atlantic basin at $47^{\circ} \mathrm{S}$ is given by $\frac{L}{f \rho} \tau$, where $f$ is the Coriolis parameter, $\rho$ - density, $L$ - zonal width of the Atlantic basin, and $\tau$ - zonal wind stress. The transport is approximately $5.5 \mathrm{~Sv}$ in both the GLOBAL and ATL2D simulations, but is zero in ATL2D_SW. The stratification in the sponge layer in ATL2D_SW is prescribed to the same values as in ATL2D.

The drastic reduction in the southern winds in ATL2D_SW leads to a significantly weakened meridional transport in the upper Southern Atlantic (Fig. 9c). The wind driven MOC cell in $\Psi_{z}$ located south of approximately $30^{\circ} \mathrm{S}$ in ATL2D is, predictably, significantly weaker in ATL2D_SW; the maximum reduction of approximately $5 \mathrm{~Sv}$ is observed at the surface. North of these latitudes, the reduction in $\Psi_{z}$ is smaller and reaches its maximum of $1.5 \mathrm{~Sv}$ at approximately 500-m depth. The maximum AMOC transport in the Northern Hemisphere is reduced by less than $1.2 \mathrm{~Sv}$ (Table 1). The difference in the maximum isopycnal streamfunction $\Psi_{\sigma}$ is even smaller and does not exceed $1 \mathrm{~Sv}$ (Fig. 9b).

The differences in the stratification are mostly contained to the upper 500 meters and to the Southern Hemisphere. Due to a significantly smaller Ekman transport, the upper thermocline in the Southern Hemisphere is noticeably shallower in ATL2D_SW than in ATL2D, especially at the southernmost latitudes. In the rest of the domain, the stratification is very similar between the two simulations. The "no-flow" surface $Z_{0}$ and deep isopycnals are only slightly deeper in ATL2D_SW than in ATL2D.

\section{c. Significance of the northern stratification}

The foregoing analysis demonstrates the importance of the isopycnal depth at the SOAtlantic boundary in shaping AMOC. As is suggested in the previous section, this role is, 
a) Zonal wind stress

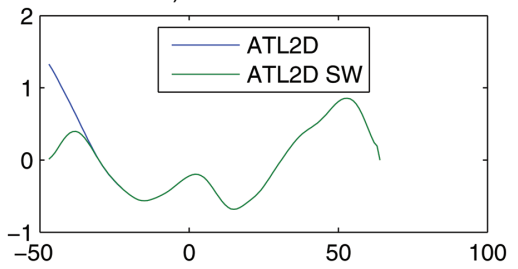

b) Max isopycnal transport

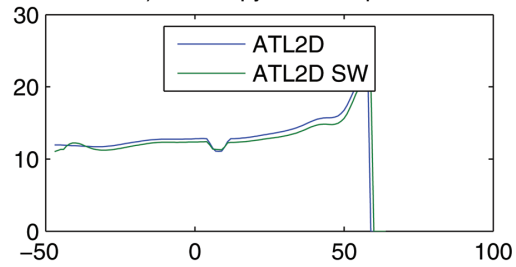

c) AMOC: ATL2D SW - ATL2D

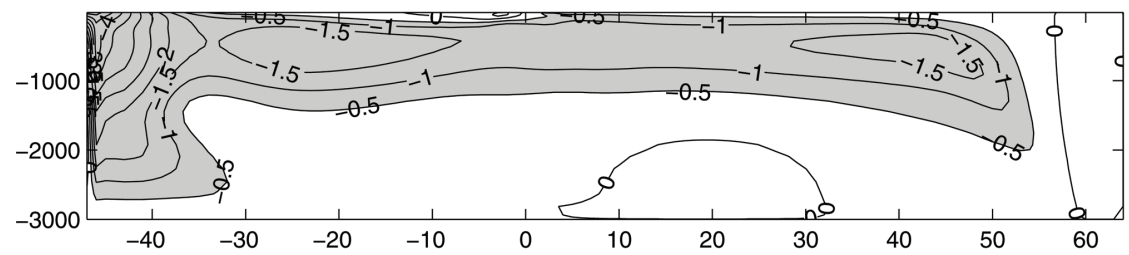

d) Stratification

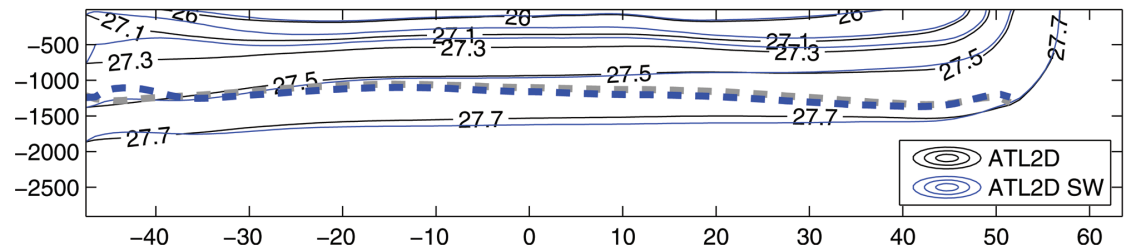

Figure 9. Direct importance of the SO-Atlantic Ekman transport in the Atlantic MOC. Panel (a) shows the zonal winds stress in the Atlantic in the standard and ATL2D_SW simulations. Panel (b) - Maximum isopycnal MOC $\left(\Psi_{\sigma}\right)$ as a function of latitude for ATL2D and ATL2D_SW. Panel (c) demonstrates the effect of reduced Ekman transport on AMOC; shown is the difference in the Atlantic meridional overturning streamfunction $\Psi_{z}$ between ATL2D_SW and ATL2D simulations. Negative values are shaded. Panel (d) shows zonally averaged potential density anomaly $\sigma_{\theta}$ (referenced to the surface) in the Atlantic for the ATL2D and ATL2D_SW simulations. Zonally averaged position of the $Z_{0}$ surface, which separates the northward- and southward-flowing branches of AMOC, is shown by the thick dashed lines.

however, a product of the interplay between the southern stratification and surface density structure in the high-latitude North Atlantic. As an illustration, we explore the role of the difference in density structure between the Atlantic and Pacific sectors of SO. The following simulation attempts to explain the difference between stratification and MOC in these two basins. In addition to drastically different upper-ocean stratification (Fig. 3c-d), mean upper-ocean stratification in the Atlantic and Pacific sectors of SO is also significantly different (Fig. 10a). In particular, the SO isopycnals with $\sigma_{\theta}<27.4$ (upper 1000 meters) in the Pacific sector are noticeably deeper than in the Atlantic sector; the depth of the isopycnals $\sigma_{\theta}>27.4$ is similar in two simulations. To address the relative significance of this difference, experiment ATL1D was repeated with the prescribed zonally uniform 
a) Density at $47^{\circ} \mathrm{S}$

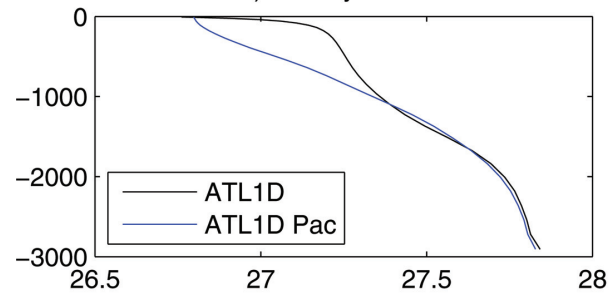

b) Max isopycnal transport

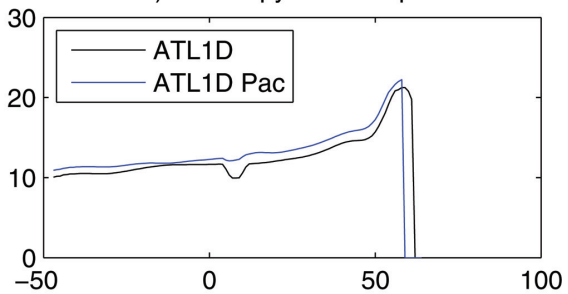

c) Stratification

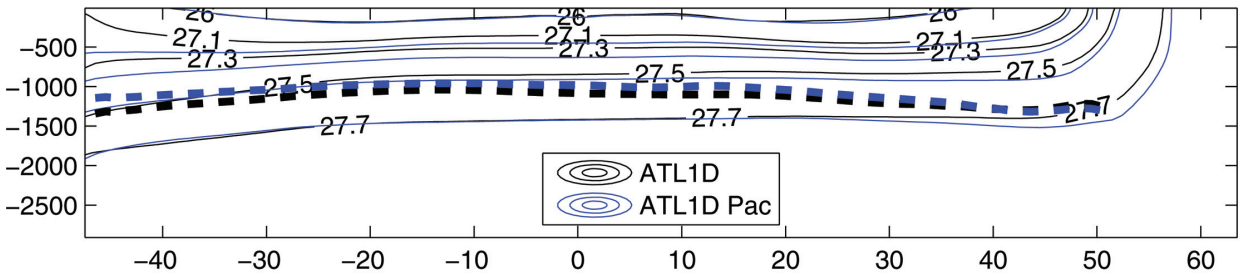

d) AMOC: ATL1D Pac - ATL1D

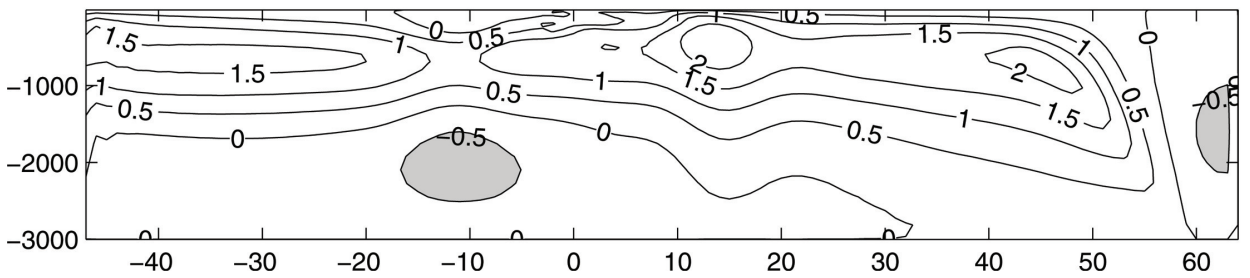

Figure 10. Significance of the difference in the southern stratification in the Atlantic and Pacific sectors of SO. Panel (a) shows the zonally averaged potential density anomaly $\sigma_{\theta}$ at $47.5 \mathrm{~S}$ in the Atlantic and Pacific sectors. Panel (b) - Maximum isopycnal MOC $\left(\Psi_{\sigma}\right)$ as a function of latitude for ATL1D and ATL1D_Pac. Panel (c) - zonally averaged potential density anomaly $\sigma_{\theta}$ (referenced to the surface) in the Atlantic for ATL1D and ATL1D_Pac. Zonally averaged position of the $Z_{0}$ surface, which separates the northward- and southward-flowing branches of AMOC, is shown by the thick dashed lines. Panel (d) shows the difference in MOC $\left(\Psi_{z}\right)$ between ATL1D_Pac and ATL1D simulations. Negative values are shaded.

SO density profile taken from the Pacific sector in SO of the GLOBAL run (experiment ATL1D_Pac).

At $47.5^{\circ} \mathrm{S}$, the isopycnals are deeper in ATL1D_Pac in the upper 1000 meters than in ATL1D (Fig. 10c), especially near the western boundary. Below 1000 meters, the stratification is very similar. Consistent with this difference in the density structure, the differences in AMOC are primarily contained in the upper 1000 meters. The isopycnal overturning $\Psi_{\sigma}$ (Fig. 10b) and z-coordinate overturning $\Psi_{z}$ (Fig. 10d) are both stronger in ATL1D_Pac than in ATL1D. The difference is, however, only $1.5 \mathrm{~Sv}(2 \mathrm{~Sv})$ for $\Psi_{\sigma}\left(\Psi_{z}\right)$ and the maximum values in the North Atlantic are very similar between the two simulations (Table 1). 
Klinger and Marotzke (1999), in their study in a single two-hemispheric basin, demonstrate the importance of the difference between the surface density in the Northern and Southern hemispheres in determining location and total transport of the deep-water formation; a large inter-hemispheric density contrast does not, however, necessarily produce a very large circulation asymmetry in their study. Although the direct comparison of their study with our asymmetric model domain $\left(47^{\circ} \mathrm{S}-64^{\circ} \mathrm{N}\right)$ is challenging here, we can quantify the interhemispheric density contrast in our study by computing the difference $\Delta \sigma_{\mathrm{SN}}$ in the depth-averaged (over upper 1000 meters) potential density at $47^{\circ} \mathrm{S}$ and $45^{\circ} \mathrm{N}$. This value is $0.15 \mathrm{~kg} \mathrm{~m}^{-3}$ in ATL1D, which is significantly smaller than in ATL1D_Pac $\left(\Delta \sigma_{\mathrm{SN}}=0.3 \mathrm{~kg} \mathrm{~m}^{-3}\right)$; this is explained by deeper isopycnals in ATL1D_Pac compared to ATL1D albeit very similar northern stratification in these two cases. Thus, stronger AMOC in ATL1D_Pac is in line with the results by Klinger and Marotzke (1999). Note also that the surface density in the North Pacific in GLOBAL simulation is significantly lower than in the North Atlantic, so the density contrast is of opposite sign in GLOBAL and in ATL1D_Pac $\left(\Delta \sigma_{\mathrm{SN}}=-0.26 \mathrm{~kg} \mathrm{~m}^{-3}\right)$.

Analysis of Section $4 \mathrm{c}$ further suggests that the Atlantic density and MOC is controlled by the isopycnal depth in the south and outcrop in the north. This point is further illustrated by an additional experiment in which the stratification is fixed not at the southern boundary of the domain, but at the Equator. In the Northern Hemisphere, where the isopycnals are once again pinned to their positions in the south and north, the resulting stratification and MOC are similar to those in GLOBAL (not shown). In contrast, in the Southern Hemisphere, where the isopycnals in the south are free to evolve, the MOC is as weak as in ATL_Free.

\section{d. Response of the MOC to a North Atlantic density anomaly}

The dynamics of the interplay between the southern and northern density structure is particularly important for the dynamics of the response of AMOC to changes in the surface conditions in the high-latitude North Atlantic. For a simple example of such change, this section examines a positive surface buoyancy anomaly - a popular scenario highly relevant to past and future climate changes. Several studies suggest that the response of the Southern Hemisphere to such an anomaly can be significantly delayed and weakened compare to the Northern Hemisphere (e.g. Zhang and Delworth, 2005). The uncertainty in these predictions is, however, rather high and the response of the Southern Ocean remains largely unknown. It is therefore of interest to examine how the steady-state Atlantic responds to a North Atlantic surface buoyancy anomaly in the model with the fixed SO stratification $\sigma_{S}$.

In a modified GLOBAL simulation (experiment GLOBAL_AN), a positive buoyancy anomaly is introduced in the North Atlantic by reducing a target salinity north of $50.5 \mathrm{~N}$ by $0.5 \mathrm{psu}$. This is an idealized version of the classical "water hosing" experiment; this reduction in target salinity is equivalent to an anomalous freshwater flux of $0.72 \mathrm{~m} \mathrm{yr}^{-1}$. Because of this decrease in the density at NADW formation sites, AMOC shifts to lighter isopycnals (Fig. 11a). As expected, the AMOC intensity is reduced substantially to the 
a) Density of the no-flow surface

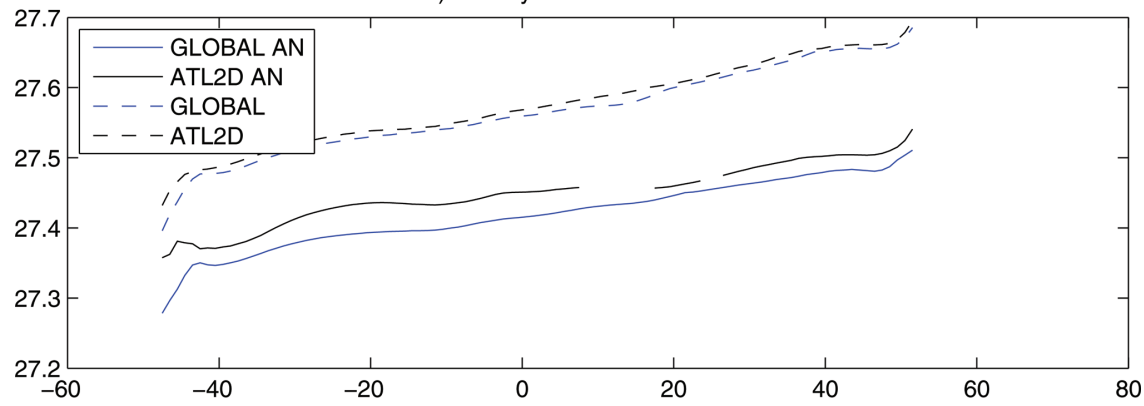

b) Isopycnal overturning at the Equator and the Push-pull mode

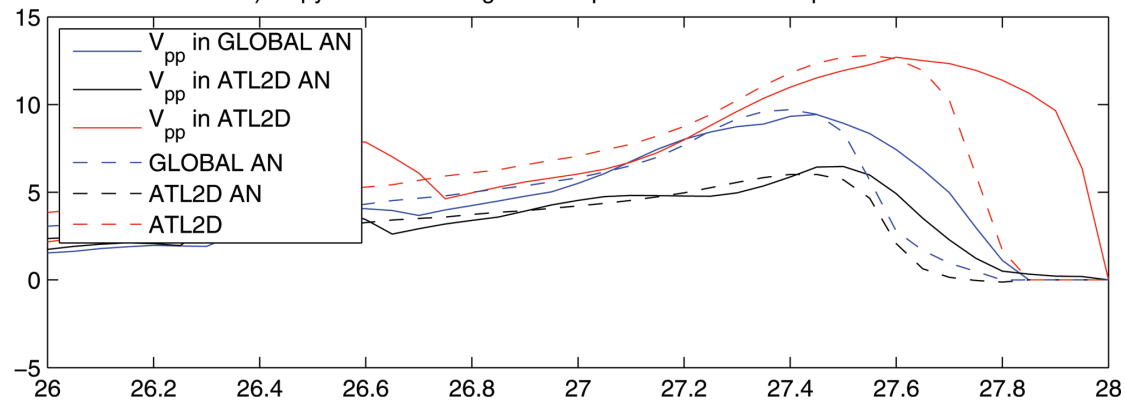

Figure 11. Effects of the North Atlantic density anomaly on the isopycnal MOC. Panel (a) shows the densities corresponding to the "no-flow" surface in GLOBAL, ATL2D, GLOBAL_AN and ATL2D_AN. Panel (b) - the push pull mode $V_{p p}$ (solid dashed) and the maximum isopycnal MOC $\left(\Psi_{\sigma}\right.$, dashed) at the equator for ATL2D, GLOBAL_AN and ATL2D_AN, as functions of density. Units are Sverdrups.

maximum value of only $16.0 \mathrm{~Sv}$ (Table 1). The isopycnal AMOC is also nearly uniformly reduced by $2.5-4 \mathrm{~Sv}$ (Fig. 11b). The isopycnals deepen almost uniformly over the entire domain, as can be seen from, for example, the stratification at the SO-Atlantic boundary (Fig. 12b). Decreased density and nearly unchanged depth of the $Z_{0}$-surface is another manifestation of the overall decrease in density in this simulation.

We next repeat the "water hosing" experiment in our hybrid Atlantic-only model (ATL2D_AN). In this simulation, $\sigma_{S}$ is kept at its "unperturbed" value from GLOBAL (and ATL2D), but the North Atlantic buoyancy anomaly is identical to the one in GLOBAL_AN. As a result of nearly the same surface densities in the North Atlantic, the $Z_{0}$ surface in ATL2D_AN corresponds to densities very similar to those in GLOBAL_AN (Fig. 11a). The $\sigma_{S}$ isopycnals are, however, prevented from the kind of deepening they exhibit in GLOBAL_AN, and most Atlantic isopycnals are shallower in ATL2D_AN as a result. In particular, the depth of the $Z_{0}$ surface in this experiment (Fig. 12a) is decreased from the average value of approximately $1200 \mathrm{~m}$ in GLOBAL, ATL2D and GLOBAL_AN to $1000 \mathrm{~m}$ in ATL2D_AN. 
a) Depth of the no-flow surface

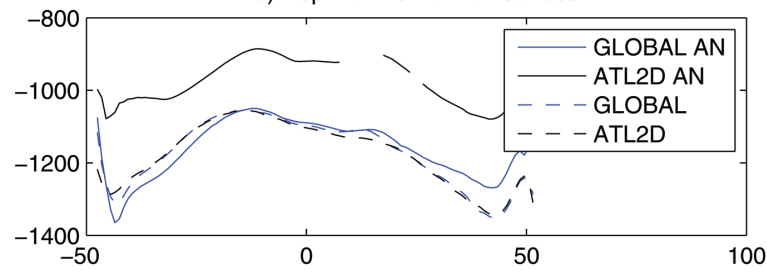

b) Density at $47.5 \mathrm{~S}$

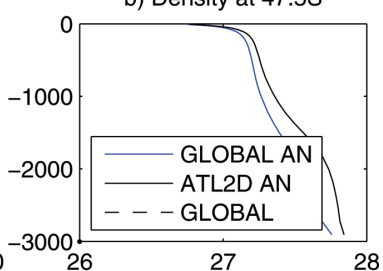

c) AMOC: GLOBAL AN

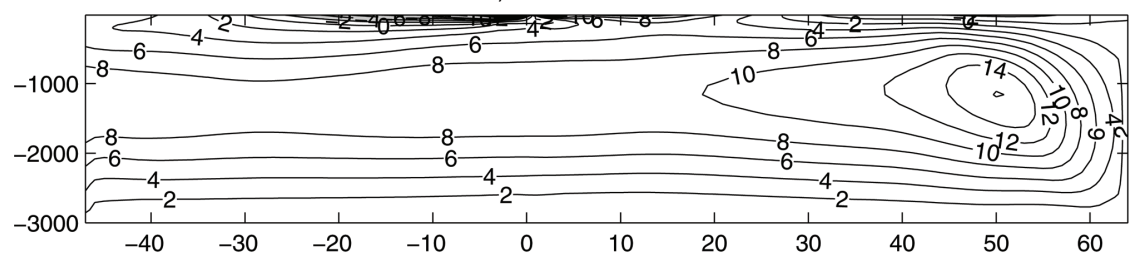

d) AMOC: ATL2D AN

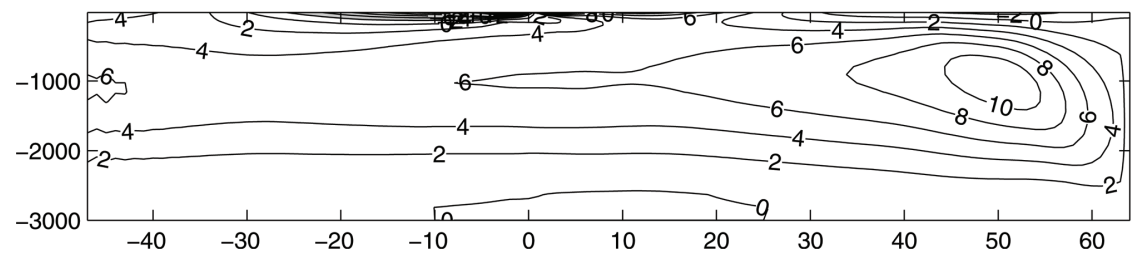

Figure 12. Effects of the North Atlantic density anomaly on the stratification and z-coordinate AMOC. Panel (a) shows the zonally averaged depth of the $Z_{0}$ surface in ATL2D, GLOBAL_AN and ATL2D_AN simulations. Panel (b) shows the zonally averaged potential density anomaly $\sigma_{\theta}$ at 47S. Two bottom panels show the Atlantic meridional overturning streamfunction $\Psi_{z}$ for (c) GLOBAL_AN and (d) ATL2D_AN simulations; units are Sverdrups. Negative values (sinking in the south) are shaded.

Consistent with this shoaling of the main isopycnals, the simulated "delay" in the SO response to a positive buoyancy anomaly acts to destabilize AMOC. Fixed $\sigma_{S}$ results in a shallower and weaker, in both isopycnal and z-coordinates, AMOC cell in ATL2D_AN relative to GLOBAL_AN (Figs. $11 \mathrm{~b}$ and $12 \mathrm{c}$,d). Maximum AMOC is reduced to $11 \mathrm{~Sv}$, down from $16 \mathrm{~Sv}$ in GLOBAL_AN and $20 \mathrm{~Sv}$ in ATL2D. The push-pull mode $V_{p p}$ shown in Figure $11 \mathrm{~b}$ further illustrates changes in the isopycnal overturning. ${ }^{5}$ The changes in the magnitude of the surface-forced push-pull mode, seen in Figure 11b, are primarily governed by changes in the surface buoyancy fluxes and density. The density corresponding to the maximum in $V_{p p}\left(\sigma_{m}\right)$ shifts to lighter densities in GLOBAL_AN and ATL2D_AN in comparison to ATL2D, as a result of the positive surface buoyancy anomaly in the North

5. Diapycnal mixing is the main cause of disagreement between the $V_{p p}$ and the isopycnal overturning (shown at the Equator); consistent with our previous discussion, it causes the shift of the no-flow surface to lighter densities. 
Atlantic. The decrease in the density of the $Z_{0}$ surface is seen as a similar shift of the maximum in $\Psi_{\sigma}$ to lighter densities.

\section{Discussion and conclusions}

The main goal of this study is to unravel complicated dynamical links that govern the interplay between the Southern Ocean (SO) and the upper cell of AMOC. Important differences in the dynamics between $\mathrm{SO}$ and Atlantic make each basin unique and distinct. The SO-Atlantic system is, of course, inherently coupled and the two basins strongly influence the circulation and stratification of each other. As in the case of other complex coupled systems, such as the atmosphere-ocean system, uncoupling of the SO-Atlantic system can, however, lead to important insights into the dynamics of each component, as well as their interplay. For example, studies of ACC forced by prescribed stratification at its northern flank led to important advances in understanding of the ACC dynamics (e.g. Marshall and Radko, 2003). In the present study, the Atlantic stratification and MOC are directly forced by the stratification at - and volume, heat and salt fluxes across - the southern boundary of the Atlantic basin. This approach allows a transparent analysis of the roles played by each of these factors.

Stratification at the SO-Atlantic boundary is demonstrated to be the key factor controlling the Atlantic stratification and upper cell of MOC. Among all aspects of the SO stratification, the isopycnal depth in general and the position of the deep isopycnals near the western boundary in particular, appear to play the leading role. The average isopycnal depth is controlled by the depth of the isopycnals in the south-west and their outcropping positions in the north-west.

Surprisingly, density structure at the eastern wall, in the model analog of the Agulhas retroflection region, appears to be of secondary importance. The asymmetry is explained by the lack of an effective direct mechanism for communication between the eastern portion of SO and the rest of the Atlantic, and the importance of northward-propagating Kelvin waves at the western wall. A south-eastern portion of an ocean basin can influence SO regions westward from it through the Rossby wave propagation (Ivchenko et al., 2004); this mechanism is, however, outside of the scope of this paper, which is focused on the direct effects of the prescribed SO stratification. Our conclusions can also be influenced by the lack of resolution in this undoubtedly important sub-region of the South Atlantic. Most notably, Agulhas eddies, whose buoyancy transport can prove to be important (e.g., Donners and Drijfhout 2004), are missing in this study. Further studies, in more realistic models, are clearly needed before a satisfying understanding of the dynamical role of the southeastern stratification can be reached.

The SO density structure is, of course, in large part a product of the volume, heat and salt exchanges across the SO-Atlantic boundary, and the prescription of the SO stratification in this study implicitly incorporates important indirect effects of these exchanges. For example, enhanced SO westerlies are expected to deepen the isopycnals, and thus act to enhance 
AMOC. These changes are, for example, observed in a coupled study by Delworth and Zeng (2008). The demonstrated small direct contribution of the Ekman volume flux to AMOC in our study is consistent with Klinger and Marotzke (2004) who showed that in the absence of an ACC-like channel, sensitivity of AMOC to winds is dramatically reduced. Our results can be used to interpret their findings as a manifestation of the primary importance of southern winds in setting SO stratification, which in turn controls AMOC. Without this effect, in the absence of ACC, the importance of the southern winds is very limited. Similarly the direct effects of heat/salt fluxes by parameterized eddies and geostrophic transports across the SO-Atlantic boundary are also demonstrated to be limited to sustaining the stratification at the SO-Atlantic boundary.

The importance of the complicated interplay between the influence of the SO stratification and surface density structure in the high-latitude North Atlantic is also clearly demonstrated by this study. In particular, the role of SO stratification in controlling AMOC response to a North Atlantic density anomaly is somewhat counter-intuitive - the variation in AMOC is amplified if SO stratification is not allowed to change. The latter result provides a new insight into the "bi-polar seesaw" theory of past climate reorganizations (e.g. Crowley, 1992; Broecker, 1998), by suggesting that a delay in SO response can act to further destabilize AMOC in the North Atlantic. This result may also suggest an additional destabilizing factor for the future AMOC state, given the recent evidence for the very limited response of SO stratification to changes in the surface winds (Meredith and Hogg, 2006). It should be noted, however, that our conclusions pertain to the steady-state response of AMOC to a density anomaly, and dynamics of the transient response shall be investigated in a separate study. The drastic difference between the Atlantic and Pacific MOCs is also clearly a consequence of the different surface density structure in two basins, rather than the density in the Atlantic and Pacific sectors of SO.

These results strongly suggest that a primary focus of successful simulations of the World Ocean shall be an accurate reconstruction of the stratification at the northern flank of SO. This study deals with a series of steady states and does not address variability. It is, however, prudent to assume that monitoring of the stratification in the Southern Atlantic, particularly in its western portion, shall be a necessary component of any observing system intended to monitor long-term changes in the AMOC. An extension of this study to eddy-resolving and fully coupled simulations is needed to quantitatively address the AMOC sensitivity to SO stratification. This study does not address rich dynamics of the lower AMOC cell - the AABW overturning. The potential importance of AABW for the deep stratification and past climate changes (e.g., England, 1993; Seidov, 2001) calls for a separate investigation.

Acknowledgments. Scientific careers of both authors have been greatly influenced and inspired by Vladimir Kamenkovich, through his teaching, guidance and personal example. IK would also like to thank him for the gift of life itself. This study was supported by the National Science Foundation (grants OCE 0623524 and 0749723). The authors would like to thank Barry Klinger and an anonymous reviewer for their comments which greatly helped to improve this manuscript. 


\section{APPENDIX A}

In the Atlantic sector, the maximum value of the push-pull mode (Radko et al., 2008) is given by:

$$
V_{p p}\left(\sigma_{m}\right)=\frac{1}{2}\left\{F_{N}\left(\sigma_{m}\right)-F_{S}\left(\sigma_{m}\right)+V_{S O}\left(\sigma_{m}\right)\right\},
$$

where $\sigma_{m}$ is the corresponding density value. In the absence of diapycnal mixing, $\sigma_{m}$ would represent the surface density corresponding to the "no-flow" $Z_{0}$ surface (Fig. 1a). The watermass transformation functions (Walin, 1982) $F_{N}$ and $F_{S}$ are defined in each hemisphere by

$$
F(\sigma)=\frac{1}{\Delta \sigma} \int_{\partial S} B(x, y) d x d y
$$

where $B$ is the surface buoyancy flux, and $\delta S$ is the surface area contained between two outcropping isopycnals $\sigma$ and $\sigma+\Delta \sigma . V_{S O}$ is the actual isopycnal MOC (3) at the SOAtlantic boundary. In (A1), we also assume that $F$ in (A2) is zero at the maximum density existing at the surface; see Radko et al. (2008) for details.

This relationship between the push-pull mode and surface fluxes is easy to observe in the case of surface $\sigma_{\theta}$ being primarily a function of latitude $y$; for infinitesimally small $\Delta \sigma$ equation (A2) can then be written as

$$
F_{N}(\sigma) \approx \frac{B\left(\sigma_{m}\right)}{d \sigma / d y} L_{x}
$$

where $L_{x}$ is the basin width. In the limit of small cross-isopycnal transport in the interior ("adiabatic MOC"), $V_{p p}$ in (A1) accurately describes the actual isopycnal MOC at all latitudes, and is equal to $F_{N}$. In this case, the maximum isopycnal MOC, which is strongly sensitive to the SO stratification, is linked to and determined by the buoyancy flux $B$ at the isopycnal surface corresponding to the maximum in the push-pull mode. Such isopycnal would be equivalent to the "no-flow" $Z_{0}$ surface in the absence of diapycnal fluxes in the interior.

\section{APPENDIX B}

The purpose of this appendix is to illustrate the importance of the isopycnal orientation at the western boundary, strongly controlled by the isopycnal depth in the south and outcrop in the north, in controlling the meridional volume transport in MOC. To illustrate this effect in the following model, we assume that the depth of each isopycnal at the western boundary $\left(\sigma_{w}\right)$ can be approximated by a linear function of the latitude. This depth decreases from the value $z_{n}$ at the southern boundary to zero at its outcrop position $y_{n}$ in the North Atlantic (Fig. B1); $y_{n}$ is fixed, but $z_{n}$ changes with $d$ according to Eq. 4 .

Next, consider a point $C$ on the $y-z$ plane in the Southern Hemisphere, which has latitude $y_{C}$ and depth $z_{C}$. Two isopycnal surfaces crossing point $\left(y_{C}, z_{C}\right)$, one at the western wall 


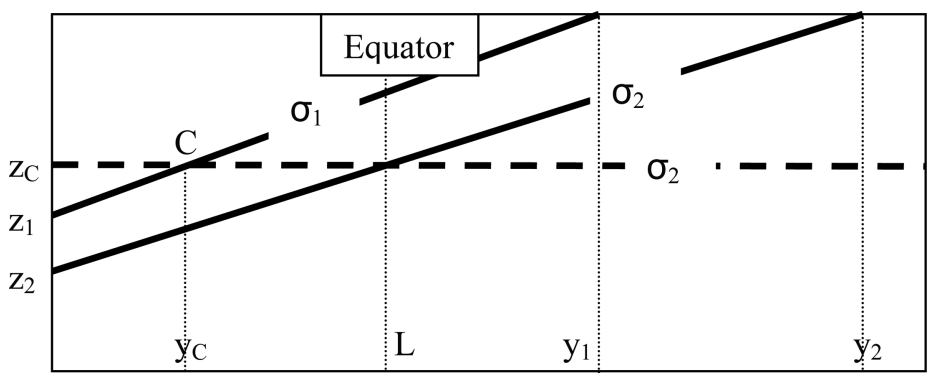

Figure B1. Schematics of the stratification in the Atlantic basin, used for deriving scaling for the zonal density/pressure difference at the point $\mathrm{C}$. Coordinate y stands for the distance from the southern boundary, and $\mathrm{z}$ - for the depth. Positions of the isopycnals at the western wall are shown by solid lines, at the eastern wall - by the dashed line.

$\left(\sigma_{1}\right)$ and ones at the eastern wall $\left(\sigma_{2}\right)$. Zonal density difference at a point $\left(y_{C}, z_{C}\right)$ will, with the help of (4) and geometric considerations, be given by:

$$
\Delta \sigma=\sigma_{2}-\sigma_{1}=\sigma_{2}-\sigma_{s}(0)\left(1-\frac{C Z_{1}}{d}\right)=\sigma_{2}-\sigma_{s}(0)\left(1-\frac{a_{1} C Z_{C}}{d}\right)
$$

where $a_{n}=y_{n} /\left(y_{n}-y_{C}\right)$.

The zonal pressure gradient $\Delta p_{w}$ and meridional geostrophic volume transport $V$ can then be scaled as

$$
\Delta p_{w} \sim g z_{C} \Delta \sigma, \quad V \sim \frac{g}{f} z_{C}^{2} \Delta \sigma
$$

Next, relate $z_{C}$ to $d$ using, once again, geometry and Eq. 4:

$$
z_{C}=z_{2} b_{2}=\frac{d}{c}\left(1-\frac{\sigma_{2}}{\sigma_{S}(0)}\right) b_{2}
$$

where $b_{n}=\left(y_{n}-L\right) / y_{n}$, and $L$ is the distance between the southern boundary and the equator. Combining (B1) and (B3) then gives the zonal density contrast that is independent of $d$ :

$$
\Delta \sigma=\left(\sigma_{2}-\sigma_{S}(0)\right)\left(1-a_{1} b_{2}\right)
$$

According to (B2), (B3) and (B4), the volume transport of AMOC $V$ increases as $d^{2}$ with deepening southern isopycnals.

\section{REFERENCES}

Broecker, W. S. 1982. Paleocean circulation during the last deglaciation: A bipolar seasaw? Paleoceanogr., 13, 119-121. 
Bryan, F. 1987. Parameter sensitivity of primitive equation ocean general circulation models. J. Phys. Oceanogr., 17, 970-985.

Crowley, T. J. 1992. North Atlantic Deep Water cools the southern hemisphere. Paleoceanogr., 7, 489-497.

Delworth, T. L. and F. Zeng. 2008. Simulated impact of altered Southern Hemisphere winds on the Atlantic meridional overturning circulation. Geophys. Res. Lett., 35, L20708, doi:10.1029/2008GL035166.

Donners, J. and S. S. Drijfhout. 2004. The Lagrangian view of South Atlantic exchange in a global ocean model compared with inverse model results. J. Phys. Oceanogr., 34, 1019-1035.

England, M. 1993. Representing the global-scale water masses in Ocean General Circulation Models. J. Phys. Oceanogr., 23, 1523-1551.

Gent, P. R. and J. C. McWilliams. 1990. Isopycnal mixing in ocean circulation models. J. Phys. Oceanogr., 20, 150-155.

Gnanadesikan, A. 1999. A simple predictive model for the structure of the oceanic pycnocline. Science, 283, 2077-2079.

Gnanadesikan, A. and R. W. Hallberg. 2000. On the relationship of the Circumpolar Current to Southern Hemisphere winds in coarse-resolution ocean models. J. Phys. Oceanogr., 30, 20132034.

Gnanadesikan, A., R. D. Slater and B. L. Samuels. 2003. Sensitivity of water mass transformation to subgridscale mixing in coarse-resolution ocean models. Geophys. Res. Lett., 30, 1967, doi:10.1029/2003GL018036.

Hallberg, R. W. and A. Gnanadesikan. 2001. An exploration of the role of transient eddies in determining the transport of a zonally re-entrant current. J. Phys. Oceanogr., 30, 3312-3330.

- 2006. The role of eddies in determining the structure and response of the wind-driven Southern Hemisphere overturning: Initial results from the modeling eddies in the Southern Ocean Project. J. Phys. Oceanogr., 36, 2232-2252.

Haney, R. L. 1971. Surface thermal boundary conditions for ocean circulation model. J. Phys. Oceanogr., 1, 241-248.

Hasumi, H. and N. Suginohara. 1999. Atlantic deep circulation controlled by heating in the Southern Ocean. Geophys. Res. Lett., 26, 1873-1876.

Henning, C. C. and G. Vallis. 2004. The effects of mesoscale eddies on the main subtropical thermocline. J. Phys. Oceanogr., 34, 2428-2443.

Ivchenko, V. O., V. B. Zalesny and M. R. Drinkwater. 2004. Can the equatorial ocean quickly respond to Antarctic sea ice/salinity anomalies? Geophys. Res. Lett., 31, L15310, doi:10.1029/2004GL020472.

Kamenkovich, I. V. and P. J. Goodman. 2000. The dependence of AABW transport in the Atlantic on vertical diffusivity. Geophys. Res. Lett., 27, 3739-3742.

Kamenkovich, I. V., J. Marotzke and P. H. Stone. 2000. Factors affecting heat transport in an Ocean General Circulation Model. J. Phys. Oceanogr., 30, 175-194.

Kamenkovich, I. V. and E. S. Sarachik. 2004. Mechanisms controlling the sensitivity of the Atlantic thermohaline circulation to the parameterization of eddy transports in an ocean GCM. J. Phys. Oceanogr., 34, 1628-1647.

Keeling, R. F. 2002. On the freshwater forcing of the thermohaline circulation in the limit of low diapycnal mixing. J. Geophys. Res., 107, doi: 10.1029/2000JC000685.

Klinger, B. A. and J. Marotzke. 1999. Behavior of double hemisphere thermohaline flows in a single basin. J. Phys. Oceanogr., 29, 382-399.

Klinger, B. A., S. Drijfhout, J. Marotzke and J. Scott. 2003. Sensitivity of basin-wide meridional overturning to diapycnal diffusion and remote wind forcing in an idealized Atlantic-Southern 
Ocean geometry. J. Phys. Oceanogr., 33, 249-266.

- 2004. Remote wind-driven overturning in the absence of the Drake Passage Effect. J. Phys. Oceanogr., 34, 1036-1049.

Ledwell, J. R., A. J. Watson and C. S. Law. 1993. Evidence for slow mixing across the pycnocline from an open-ocean tracer-release experiment. Nature, 364, 701-703.

Levitus, S. and T. P. Boyer. 1994. World Ocean Atlas 1994, NOAA Atlas NESDIS 4, 117 pp.

Luyten, J. R., J. Pedlosky and H. Stommel. 1983. The ventilated thermocline. J. Phys. Oceanogr., 13, 292-309.

Marotzke, J. and B. A. Klinger. 2000. Dynamics of equatorially asymmetric thermohaline circulations. J. Phys. Oceanogr., 30, 950-970.

Marshall, J. and T. Radko. 2003. Residual-mean solutions for the Antarctic Circumpolar Current and its associated overturning circulation. J. Phys. Oceanogr., 33, 2341-2354.

McDermott, D. A. 1996. The regulation of Northern overturning by Southern Hemisphere winds. J. Phys. Oceanogr., 26, 1234-1255.

Meredith, M. P. and A. Hogg. 2006. Circumpolar response of Southern Ocean eddy activity to a change in the Southern Annular Mode. Geophys. Res. Lett., doi:10.1029/2006GL026499.

Pacanowski, R. C. and S. M. Griffies. 1999. MOM 3 manual, technical report, GFDL/NOAA, Princeton, NJ.

Radko, T. 2007. A mechanism for establishment and maintenance of the meridional overturning in the upper ocean. J. Mar. Res., 65, 85-116.

Radko, T. and I. Kamenkovich. 2011. Semi-adiabatic model of the deep stratification and meridional overturning. J. Phys. Oceanogr., 41, 751-780.

Radko, T., I. V. Kamenkovich and P.-Y. Dare. 2008. Inferring the pattern of meridional transport from the air-sea fluxes. J. Phys. Oceanogr., 38, 2722-2738.

Saenko O. A., A. J. Weaver and J. M. Gregory. 2003. On the link between the two modes of the ocean thermohaline circulation and the formation of global-scale water properties. J. Climate, 16, 2797-2801.

Samelson, R. M. 2004. Simple mechanistic models of mid-depth meridional overturning. J. Phys. Oceanogr., 34, 2096-2103.

- 2009. A simple dynamical model of the warm-water branch of the mid-depth meridional overturning cell. J. Phys. Oceanogr., 39, 1216-1230.

Seidov, D., E. Barron and B. J. Haupt. 2001. Meltwater and the global ocean conveyor: Northern versus southern connections. Global Planet. Change, 30, 257-270.

Sévellec, F. and A. V. Fedorov. 2011. Stability of the Atlantic meridional overturning circulation in a zonally-averaged ocean model: the effects of freshwater flux, wind stress, and diapycnal diffusivity. Deep-Sea Res., 58, 1927-1943.

Talley, L. D. 2003. Shallow, intermediate, and deep overturning components of the global heat budget. J. Phys. Oceanogr., 33, 530-560.

Toggweiler, J. R. and B. Samuels. 1995. Effect of Drake Passage on the global thermohaline circulation. Deep-Sea Res., 42, 477-500.

- 1998. On the ocean's large-scale circulation near the limit of no vertical mixing. J. Phys. Oceanogr., 28, 1832-1852.

Toole, J., K. Polzin and R. Schmitt. 1994. Estimates of diapycnal mixing in the abyssal ocean. Science, 264, 1120-1123.

Tsujino H. and N. Suginohara. 1999. Thermohalie circulation enhanced by wind forcing. J. Phys. Oceanogr., 29, 1506-1516.

Walin, G. 1982. On the relation between sea-surface heat flow and thermal circulation in the ocean. Tellus, 34, 187-195. 
Wang, X., P. H. Stone and J. Marotzke. 1999. Global thermohaline circulation. Part I: Sensitivity to atmospheric moisture transport. J. Climate., 12, 71-82.

Weijer, W., W. P. M. de Ruijter and H. A. Dijkstra. 2001. Stability of the Atlantic overturning circulation: Competition between Bering Strait freshwater flux and Agulhas heat and salt sources. J. Phys. Oceanogr., 31, 2385-2402.

Weijer, W., W. P. M. de Ruijter, H. A. Dijkstra and P. J. van Leeuwen. 1999. Impact of interbasin exchange on the Atlantic overturning circulation. J. Phys. Oceanogr., 29, 2266-2284.

Wolfe, C. L. and P. Cessi. 2010. What sets the strength of the middepth stratification and overturning circulation in eddying ocean models? J. Phys. Oceanogr., 40, 1520-1538.

Zhang, R. and T. L. Delworth. 2005. Simulated tropical response to a substantial weakening of the Atlantic thermohaline circulation. J. Climate, 18, 1853-1860.

Received: 18 January, 2011; revised: 20 July, 2011. 